\title{
Phytohormone and integrated mRNA and miRNA transcriptome analyses and differentiation of male between hermaphroditic floral buds of andromonoecious Diospyros kaki Thunb
}

\author{
Huawei $\mathrm{Li}^{1,2,3+}$, Liyuan Wang ${ }^{4 \dagger}$, Yini Mai ${ }^{1,2,3}$, Weijuan Han ${ }^{1,2,3}$, Yujing Suo ${ }^{1,2,3}$, Songfeng Diao ${ }^{1,2,3}$,
} Peng Sun ${ }^{1,2,3^{*}}$ and Jianmin $\mathrm{Fu}^{1,2,3^{*}}$

\begin{abstract}
Background: Persimmon (Diospyros kaki Thunb.) has various labile sex types, and studying its sex differentiation can improve breeding efficiency. However, studies on sexual regulation patterns in persimmon have focused mainly on monoecy and dioecy, whereas little research has been published on andromonoecy. In order to reveal the sex differentiation regulation mechanism of andromonoecious persimmon, we performed histological and cytological observations, evaluated OGl and MeGl expression and conducted phytohormones assays and mRNA and small RNA transcriptome analyses of the male and hermaphroditic floral buds of the andromonoecious persimmon 'Longyanyeshi 1'.

Results: Stages 2 and 4 were identified as the critical morphological periods for sex differentiation of 'Longyanyeshi 1 ' by histological and cytological observation. At both stages, OG/ was differentially expressed in male and hermaphroditic buds, but $\mathrm{MeG} /$ was not. This was different from their expressions in dioecious and monoecious persimmons. Meantime, the results of phytohormones assays showed that high IAA, $\mathrm{ABA}, \mathrm{GA}_{3}$, and JA levels at stage 2 may have promoted male floral bud differentiation. However, high JA levels at stage 4 and high ZT levels at stages 2 and 4 may have promoted hermaphroditic floral bud differentiation. In these phytohormone biosynthesis and signaling pathways, 52 and 54 differential expression genes (including AuXIAA, ARFs, DELLA, AHP, A-ARR, B-ARR, CYP735A, CRE1, PP2C, JAZ, MYC2, COI1, CTR1, SIMKK, ACO, and MPK6) were identified, respectively. During the development of male floral buds, five metacaspases genes may have been involved in pistil abortion. In addition, MYB, FAR1, bHLH, WRKY, and MADS transcription factors might play important roles in persimmon floral bud sex differentiation. Noteworthy, miR169v_1, miR169e_3, miR319_1, and miR319 were predicted to contribute to phytohormone biosynthesis and signaling pathways and floral organogenesis and may also regulate floral bud sex differentiation.

(Continued on next page)
\end{abstract}

\footnotetext{
* Correspondence: sunpeng1017@126.com; fjm371@163.com

'Huawei Li and Liyuan Wang contributed equally to this work.

'Key Laboratory of Non-timber Forest Germplasm Enhancement \& Utilization of State Administration of Forestry and Grassland, No. 3 Weiwu Road, Jinshui District, Zhengzhou 450003, China

Full list of author information is available at the end of the article
}

(c) The Author(s). 2021 Open Access This article is licensed under a Creative Commons Attribution 4.0 International License, which permits use, sharing, adaptation, distribution and reproduction in any medium or format, as long as you give appropriate credit to the original author(s) and the source, provide a link to the Creative Commons licence, and indicate if changes were made. The images or other third party material in this article are included in the article's Creative Commons licence, unless indicated otherwise in a credit line to the material. If material is not included in the article's Creative Commons licence and your intended use is not permitted by statutory regulation or exceeds the permitted use, you will need to obtain permission directly from the copyright holder. To view a copy of this licence, visit http://creativecommons.org/licenses/by/4.0/ The Creative Commons Public Domain Dedication waiver (http://creativecommons.org/publicdomain/zero/1.0/) applies to the data made available in this article, unless otherwise stated in a credit line to the data. 
(Continued from previous page)

Conclusion: The present study revealed the differences in morphology and phytohormones content between male and hermaphroditic floral buds of 'Longyanyeshi 1' during the process of sex differentiation, and identified a subset of candidate genes and miRNAs putatively associated with its sex differentiation. These findings can provide a foundation for molecular regulatory mechanism researching on andromonoecious persimmon.

Keywords: Diospyros kaki, Andromonoecy, Sex differentiation, Phytohormone, mRNA, miRNA

\section{Background}

Persimmon (Diospyros kaki Thunb.) is one of the important fruit species in China [1]. However, the persimmon industry has been affected by short fruiting periods, low shelf life, and transportation difficulties. Therefore, strengthening the cultivation of superior varieties is an important way to improve the development of the persimmon industry. Crossbreeding is an important means of germplasm innovation and thoroughbred breeding. However, there are no fruits in the male plant, and it is difficult to induce the conversion of male to female plant by artificial regulation in persimmon [2]. As a result, the selection of hybrid male parent with important economic traits is difficult, which limits the development of crossbreeding. Andromonoecy is the intermediate type of sexual system between the monoecious and dioecious type [3]. Andromonoecious persimmon can be used to study the regulation mechanism of sex differentiation, and these types of studies can serve as a guide for inducing the transition from male to andromonoecious plant and for cultivating hermaphroditic floral buds that bear fruits. This can also improve the efficiency of hybrid male parent selection and promote the development of crossbreeding.

Extensive research on sex differentiation in persimmon has been conducted in recent years. Diospyros lotus is a diploid and closely related to D. kaki. In the former, a microRNA encoded by the pseudogene OGI on the $\mathrm{Y}$ chromosome inhibits the expression of the autosomal transcription factor $M e G I$ and male flowers development [4]. In hexaploid persimmons, OGI is nearly silenced by the insertion of ' $k a l i$ ' into its promoter. DNA methylation level of the MeGI promoter determines MeGI expression and flower sex [5]. In the monoecious persimmon 'Zenjimaru', male and female flower development was divided into 11 stages progressing between June of one year and May of the following year. This process is characterized by key morphological periods in mid-June and the following mid-April [6]. High $\mathrm{GA}_{3}$ content is positively correlated with the formation of male floral buds, and high levels of $\mathrm{ZT}$ and ABA may promote the differentiation of female floral buds in persimmon [7].

Various phytohormones regulate flower development and sex differentiation. Gibberellins are usually considered to be masculinizing phytohormones, whereas ethylene generally has a feminizing effect [8]. Interactions between auxin and cytokinins determine flower types in several plant species [9]. Synergy between brassinolide and jasmonate inhibits tassel development in the male maize flower $[10,11]$. Exogenous plant growth regulators or inhibitors alter the sex of Cannabis sativa [12], Spinacia oleracea [13], and Carica papaya [14].

MiRNAs participate in several regulatory pathways controlling plant reproductive development. MiR156 and miR172 are associated with Arabidopsis and maize flowering time [15, 16]. MiR172 regulates Arabidopsis flower development by targeting APETALA2 [17]. In maize, IDS1 translation is inhibited by ts4 miRNA (miRNA172) and results in male florets. In contrast, a loss of-function mutation of $t s 4$ or a mutation of the ids 1 miRNA binding site produces normal IDS1 protein and results in the formation of female florets $[18,19]$.

Several previous studies have elucidated sex differentiation in monoecious and dioecious persimmons. Nevertheless, the sex regulation mechanism in the andromonoecious persimmon 'Longyanyeshi 1' (with hermaphroditic and male flowers) is unknown (Fig. 1) [20]. Here, the male and hermaphroditic floral buds of 'Longyanyeshi 1', which were in the critical morphological periods for sex differentiation, were used for phytohormones assays and mRNA and small RNA transcriptome analyses to identify the regulatory roles of phytohormones, candidate genes, and miRNAs in sex differentiation of andromonoecious persimmon. This study provides valuable information for further exploration of sex differentiation of the peculiar andromonoecious persimmon.

\section{Results \\ Morphological comparison of male and hermaphroditic floral buds}

The bud scales of the 'Longyanyeshi 1' persimmon tree in Yuanyang County, Henan Province loosened and turned green on March 28. As the floral buds grew and developed, three-flower cymes were fully exposed by April 6. The floral bud sepals everted by April 14. Between April 14 and April 20, the floral buds expanded and grew but did not change in appearance. On April 23, the sepals opened and yellow-white petals appeared. The floral buds bloomed on May 3 (Fig. 2).

Four representative stages were selected to describe the internal morphological differences between male and hermaphroditic floral buds. Stamen and carpel primordia 
were observed in the male and hermaphroditic floral buds at stage 1 (March 28-31) (Fig. 3a). At stage 2 (April 1-6), stamen primordia in the male floral buds differentiated into anther primordia and carpel primordia differentiated into styles and stigmata without basal ovaries or ovules (Fig. 3b). By stage 3 (April 8-10), anther primordia differentiated into filament and anther compartments and carpel primordia elongated slightly (Fig. 3c). After anther primordium differentiation during stage 4 (April 17-20), microspore mother cells entered meiosis and pistils stopped growing and were aborted (Fig. 3d). The stamen primordia at stage 2 of the hermaphroditic floral buds differentiated into anthers and carpel primordia differentiated into style, stigma, ovary, and ovule primordia (Fig. 3e). The stamen primordia at stage 3 differentiated into filament and anther compartments, and ovule primordia bulged and bent downwards to form basal funicles (Fig. 3f). By stage 4, the stamens and pistils were normally developed and were not aborted (Fig. 3g).

Stamen development in the male and hermaphroditic floral buds was synchronous. However, the fates of the pistils differed between the two sexual phenotypes. In the male floral buds, there were neither ovule or ovary primordia in the stage 2 carpels and the carpels were aborted by stage 4 . In contrast, the carpels developed normally during the entire hermaphroditic floral bud development process. Hence, stages 2 and 4 are crucial morphological periods for sex differentiation in 'Longyanyeshi 1'. We collected male and hermaphroditic floral buds at both of these stages for subsequent comparative analysis of their $O G I$ and $M e G I$, endogenous phytohormone levels and mRNA and small RNA transcriptome expression levels.

\section{Differential expression analysis of $O G I$ and $M e G I$}

OGI is a pseudogene encoding only small RNA. It is highly homologous to MeGI. To estimate the expression levels of $O G I$ in the male and hermaphroditic floral buds of andromonoecious persimmon, we calculated the accumulation levels of small RNAs on the OGI and MeGI genomic sequences in both floral bud types (Fig. 4). The results showed that small RNA accumulation levels in the $O G I$ and $M e G I$ genomic sequences of male floral buds were higher than those for the hermaphroditic floral buds at stages 2 and 4 (Fig. 5; Fig. 6). Thus, the expression levels of OGI in the male floral buds were higher than those in the hermaphroditic floral buds at these stages. However, there were no differences between male and hermaphroditic floral buds in terms of their MeGI expression levels at these stages according to the transcriptome and RT-qPCR analyses (Fig. 7).

\section{Phytohormone content in male and hermaphroditic floral buds}

To establish the effects of endogenous phytohormones on floral bud sex differentiation, we measured indole-3acetic acid (IAA), abscisic acid (ABA), gibberellin 3 $\left(\mathrm{GA}_{3}\right)$, jasmonic acid (JA), and zeatin (ZT) in male hermaphroditic floral buds at stages 2 and 4. The IAA, $\mathrm{ABA}$, and $\mathrm{GA}_{3}$ levels in the male floral buds were markedly higher than those in the hermaphroditic floral buds at stage 2. However, there were no substantial differences between the two floral bud sexes in terms of their phytohormone levels at stage 4 . JA level was higher in the male floral buds than it was in the hermaphroditic floral buds at stage 2. However, the opposite was true for stage 4 . ZT levels were $\sim 3.5$-fold and $\sim 3.2$-fold higher in the hermaphroditic floral buds than in the male floral buds at stages 2 and 4, respectively (Fig. 8).

\section{Transcriptome sequencing}

To identify the mRNA expression profiles in male and hermaphroditic floral buds, we constructed $12 \mathrm{cDNA}$ libraries at stages 2 (MA1, MA2, and MA3 for the male and HA1, HA2, and HA3 for the hermaphroditic) and 4
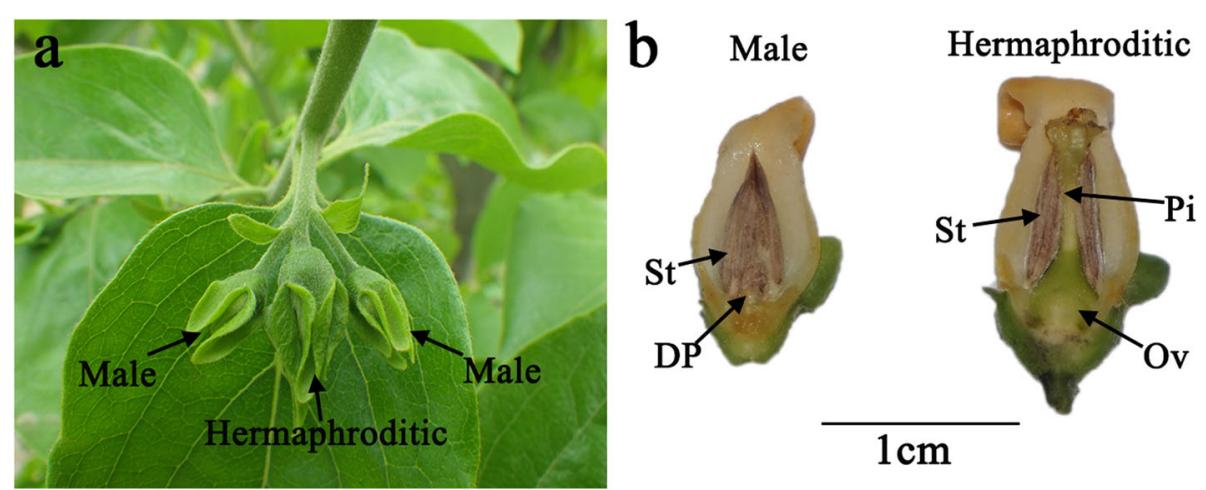

Fig. 1 Male and hermaphroditic 'Longyanyeshi 1' floral buds. a Three-flower cyme. b Male and hermaphroditic floral bud anatomy. St: stamen; DP: defective pistil; Pi: pistil; Ov: ovary 


\section{8

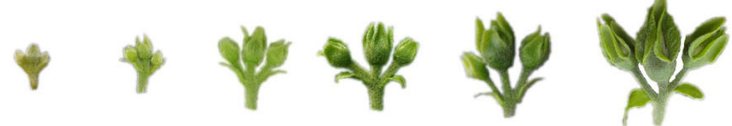 \\ Mar.28 Apr.1 Apr.6 Apr.8 Apr.14 Apr.17 Apr.20 \\ Fig. 2 External morphological changes of the 'Longyanyeshi 1' floral buds

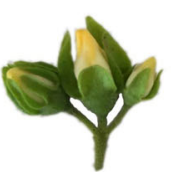 \\ Apr.23

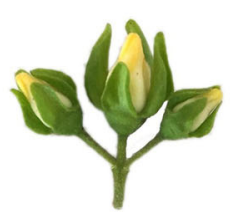 \\ Apr.25

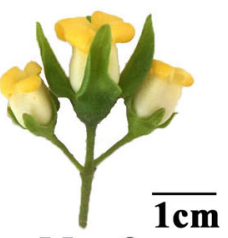 \\ May.3}

(MB1, MB2, and MB3 for the male and HB1, HB2, and HB3 for the hermaphroditic) using total RNA and sequenced them on the BGISEQ-500 platform. A total of $44.42,44.04,44.32,44.41,42.65,44.05,44.40,44.20$, $42.75,45.88,44.00$, and $42.47 \mathrm{Mb}$ clean reads, respectively, were obtained after eliminating low-quality reads (Additional file 1: Table S1). Quality control was performed and the clean reads of the 12 libraries were assembled into 82,910 unigenes with an average length of 1376 bp (Additional file 2: Table S2). Among these, 22,768 unigenes were 200-500 bp long, 17,447 unigenes were $500-1000 \mathrm{bp}$ long, and 42,695 unigenes were $<1000$ bp long (Additional file 3: Fig. S1).

The assembled unigenes were annotated via BLAST in seven public databases (NR, NT, Swissprot, Kyoto Encyclopedia of Genes and Genomes (KEGG), KOG, Pfam, and Gene Ontology (GO)) and 62,021 (74.81\%), 50,224 (60.58\%), 46,639 (56.25\%), 49,790 (60.05\%), 49, 614 (59.84\%), 47,121 (56.83\%), and 34,735 (41.89\%) were aligned, respectively. A total of 64,355 unigenes accounting for $77.62 \%$ of the total were annotated in $\geq 1$ public database (Additional file 4: Table S3).

Here, 3684 DEGs were identified between the male and hermaphroditic floral buds. Compared with the hermaphroditic floral buds, 790 genes were upregulated and 855 were downregulated in the male floral buds at stage 2 and 1341 genes were upregulated and 1185 were downregulated at stage 4 (Fig. 9).

A GO analysis of the DEGs between the male and hermaphroditic floral buds at stage 2 disclosed enrichment in 20 categories. The most abundant GO categories were oxidoreductase activity (GO:0016491; 36 unigenes), calcium ion binding (GO:0005509; 26), and iron ion binding (GO: 0005506; 21) (Fig. 10a). The most highly enriched KEGG pathways in the male floral buds compared with the hermaphroditic floral buds were plant hormone signal transduction (57 unigenes), starch and sucrose metabolism (45), and RNA degradation (28) (Fig. 10b). For stage 4, the DEGs were classified by GO analysis into 20 categories. The most abundant were transcription, DNA-templated

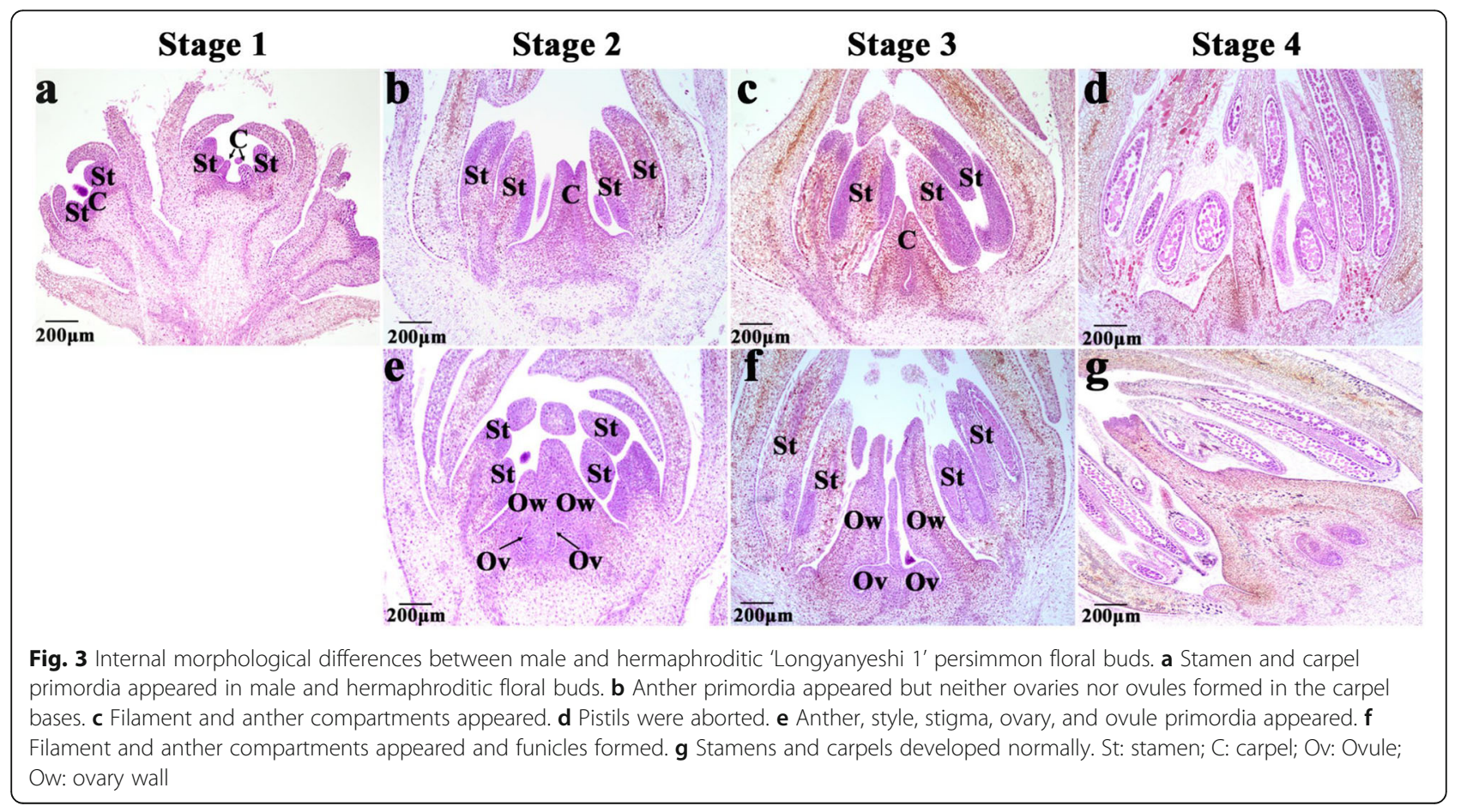




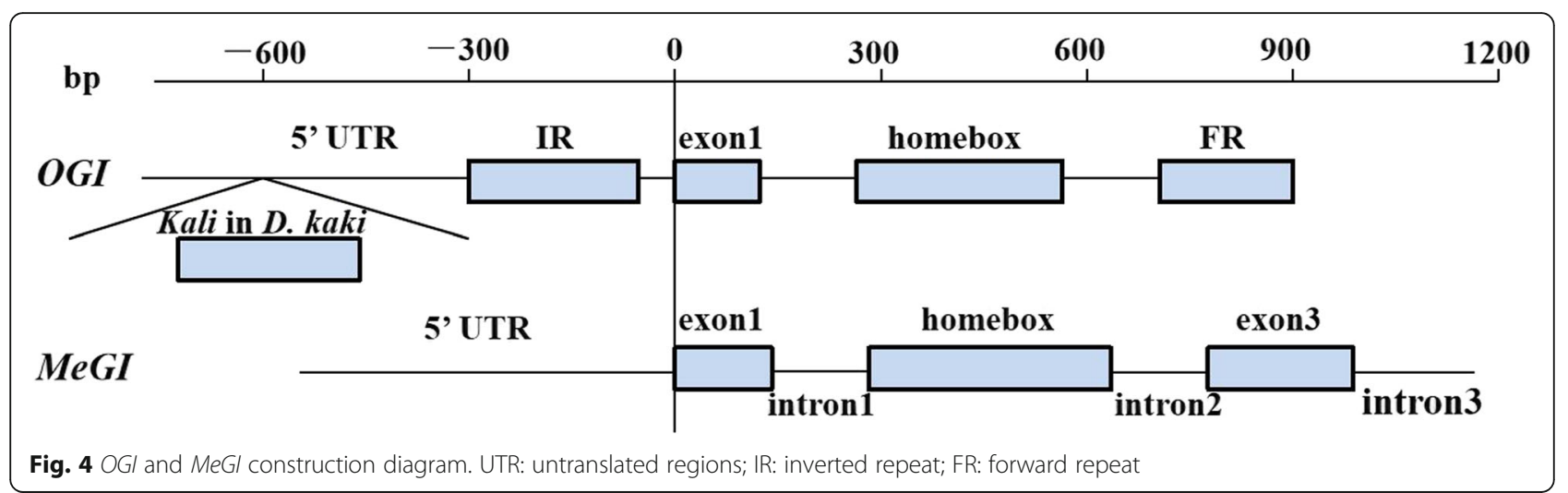

(GO:0006351; 92 unigenes), DNA binding transcription factor activity (GO:0003700; 57), and sequence-specific DNA binding (GO:0043565; 45) (Fig. 10c). Enriched KEGG pathways of the DEGs were plant hormone signal transduction (101 unigenes), plant-pathogen interaction (82), and MAPK signaling pathway-plant (70) (Fig. 10d).
Identification of differentially expressed transcription factors

Ninety-five transcription factors (TFs) belonging to 22 TF families and 183 TFs belonging to 33 TF families were differentially expressed at stages 2 and 4, respectively (Additional file 5: Table S4). MYB, FAR1, and

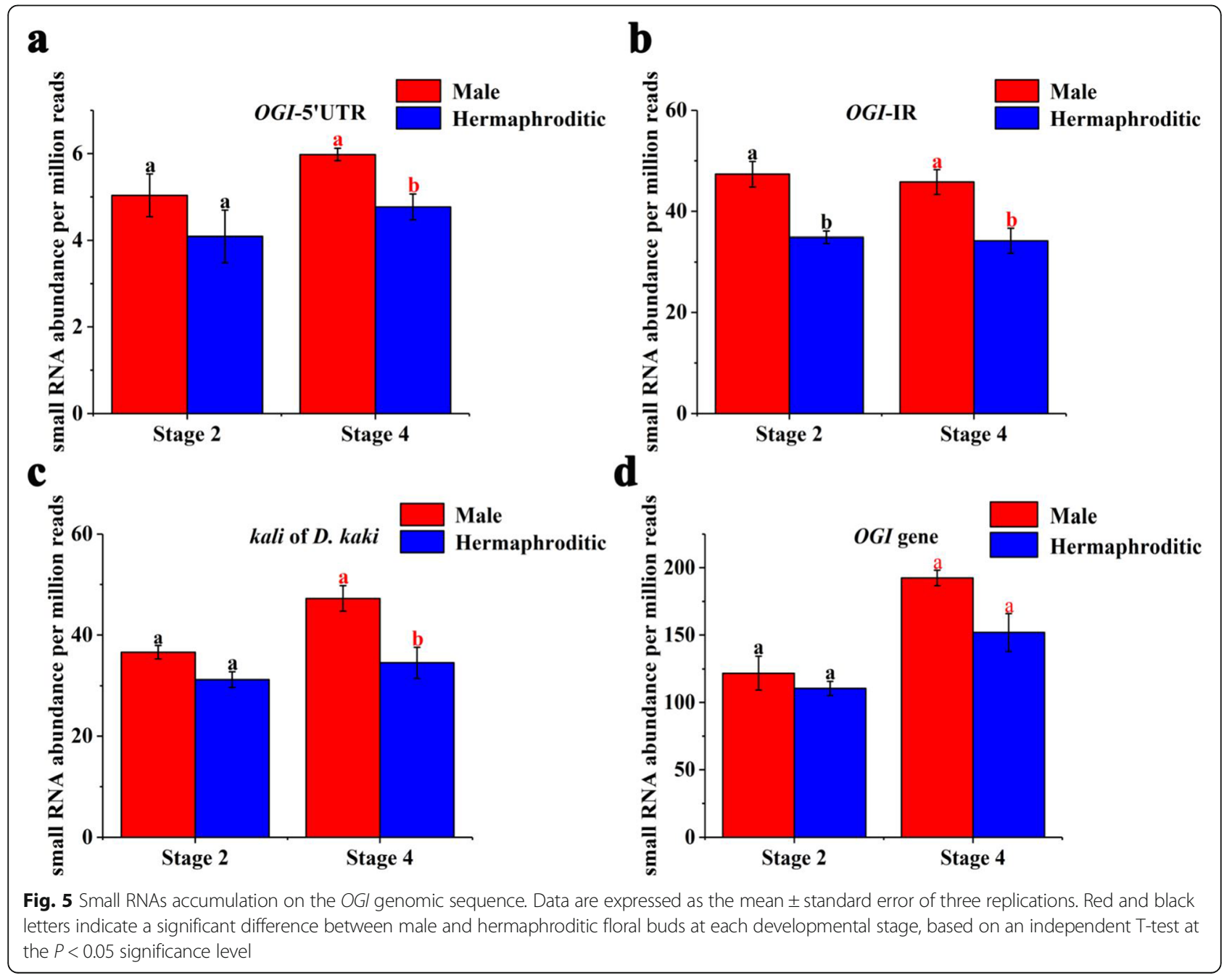


$\mathbf{a}$

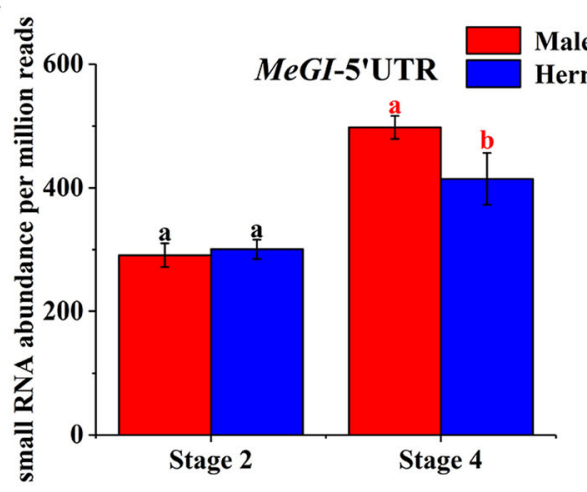

c

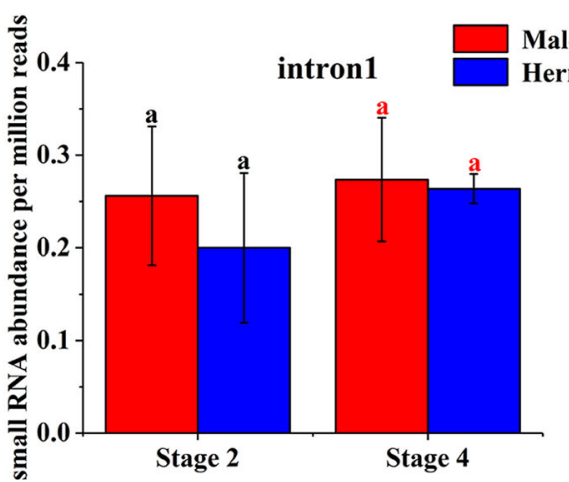

e

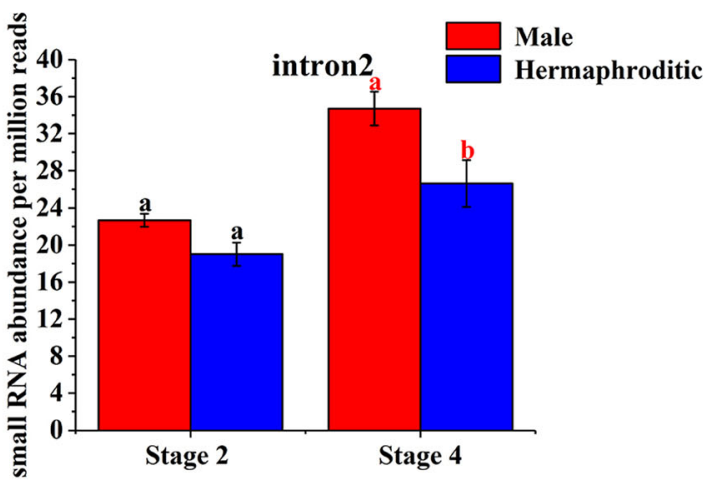

g

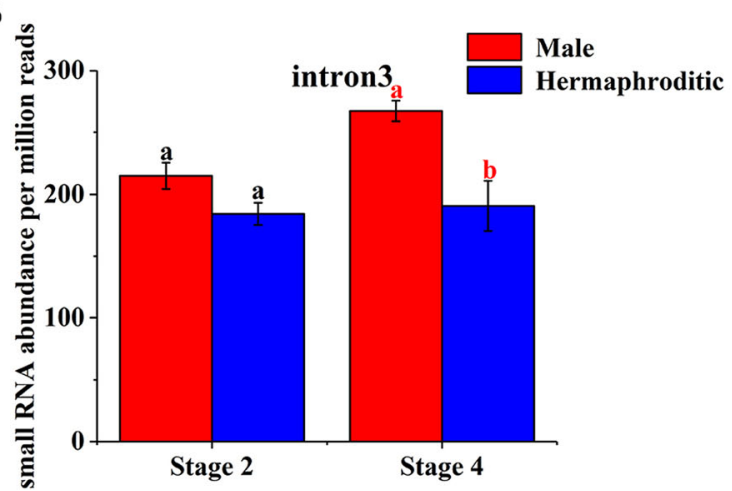

b

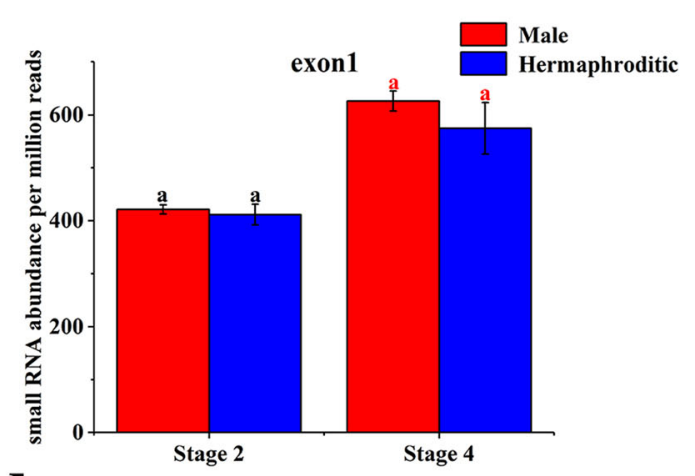

d
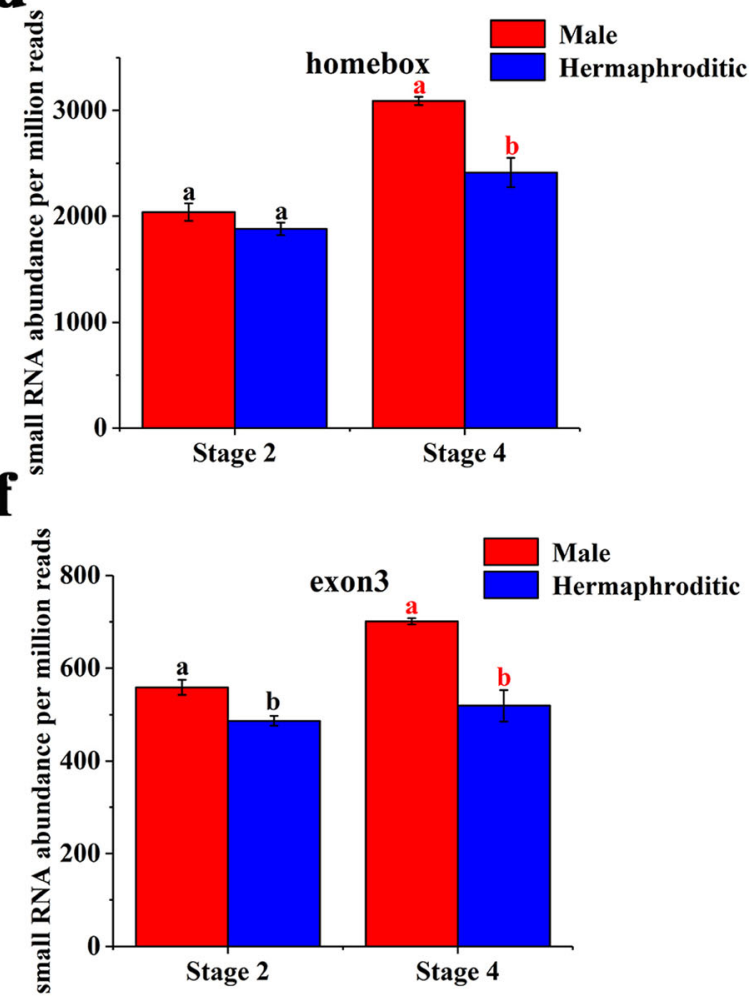

Fig. 6 Small RNA accumulation on the MeGl genomic sequence. Data are expressed as the mean \pm standard error of three replications. Red and black letters indicate a significant difference between male and hermaphroditic floral buds at each developmental stage, based on an independent T-test at the $P<0.05$ significance level 


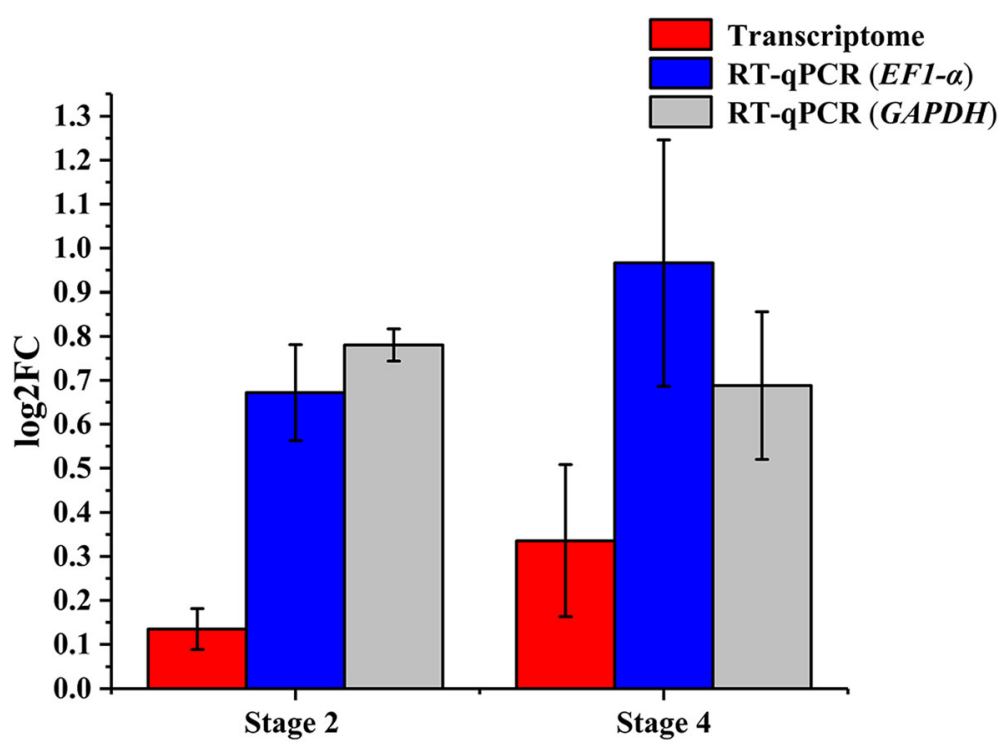

Fig. 7 Differential expression of MeGl. FC, fold change

$b H L H$ were enriched at stage 2 and $M Y B, b H L H$, and WRKY were enriched at stage 4 . Fifty-two TFs were upregulated and 43 were downregulated in male floral buds at stage 2. Ninety-three TFs were upregulated and 91 were downregulated in male floral buds at stage 4 (Fig. 11).

\section{DEGs related to phytohormone biosynthesis and signaling pathways}

The combining of the phytohormone and transcriptome analyses revealed 52 and 54 DEGs related to phytohormone biosynthesis and signaling pathways at stages 2 and 4 , respectively. In the male floral buds, 13 DEGs were upregulated and 39 DEGs were downregulated at stage 2, whereas 33 DEGs were upregulated and 21 DEGs were downregulated at stage 4 (Additional file 6: Table S5). The expression levels of the DEGs at stages 2 and 4 are depicted in a heat map (Fig. 12).

In the auxin signaling pathways, the $A U X / I A A$ genes and one of the ARFs (CL2880.Contig4_All) were upregulated, whereas the other ARF (CL2880.Contig6_All) was downregulated in the male floral buds at stage 2 .

In the gibberellin signaling pathways, the DELLA genes and one TF (CL4250.Contig11_All) were highly upregulated in the male floral buds at stage 2 .

In the cytokinin biosynthesis and signaling pathways, the AHP, $A-A R R$, and CYP735A genes were downregulated in the male floral buds at stage 2. The CRE1 and $A H P$ genes were upregulated and the $A-A R R$ and $C Y P 735 A$ genes were downregulated in the male floral buds at stage 4 .

In the abscisic acid signaling pathways, the $P P 2 C$ gene was upregulated in the male floral buds at stage 2 .
In the jasmonate signaling pathways, the $J A Z$ and $M Y C 2$ genes were upregulated and downregulated, respectively, in the male floral buds at stage 2. The COII and one JAZ (CL634.Contig3_All) genes were downregulated in the male floral buds at stage 4.

Ethylene is important for sex differentiation in plants. Here, the DEGs associated with ethylene biosynthesis and signaling pathways were also identified. The CTR1, $S I M K K$, and $A C O$ genes were downregulated in the male floral buds at stage 2, whereas the CTR1 and MPK6 genes were upregulated and the $A C O$ genes were downregulated in the male floral buds at stage 4 .

\section{DEGs related to programmed cell death}

Programmed cell death (PCD) is responsible for the abortion of inappropriate sex organs in persimmon floral buds and leads to the formation of unisexual flowers [21]. Five DEGs belonging to the metacaspase family were identified at stage 4 . Among these, three were upregulated and two were downregulated in the male floral buds (Table 1).

\section{MiRNA sequencing}

Twelve small RNA libraries at stages 2 (MA1, MA2, and MA3 for the male and HA1, HA2, and HA3 for the hermaphroditic) and 4 (MB1, MB2, and MB3 for the male and HB1, HB2, and HB3 for the hermaphroditic) were constructed with total RNA and sequenced on the BGISEQ-500 platform to investigate miRNA differentiation between the male and hermaphroditic floral buds. After removing invalid adapter and low-quality sequences, 28,031,142, 28,702,111, 27,811,471, 27,071,649, $28,343,565,28,194,623,27,935,952,27,231,677,27,100$, 


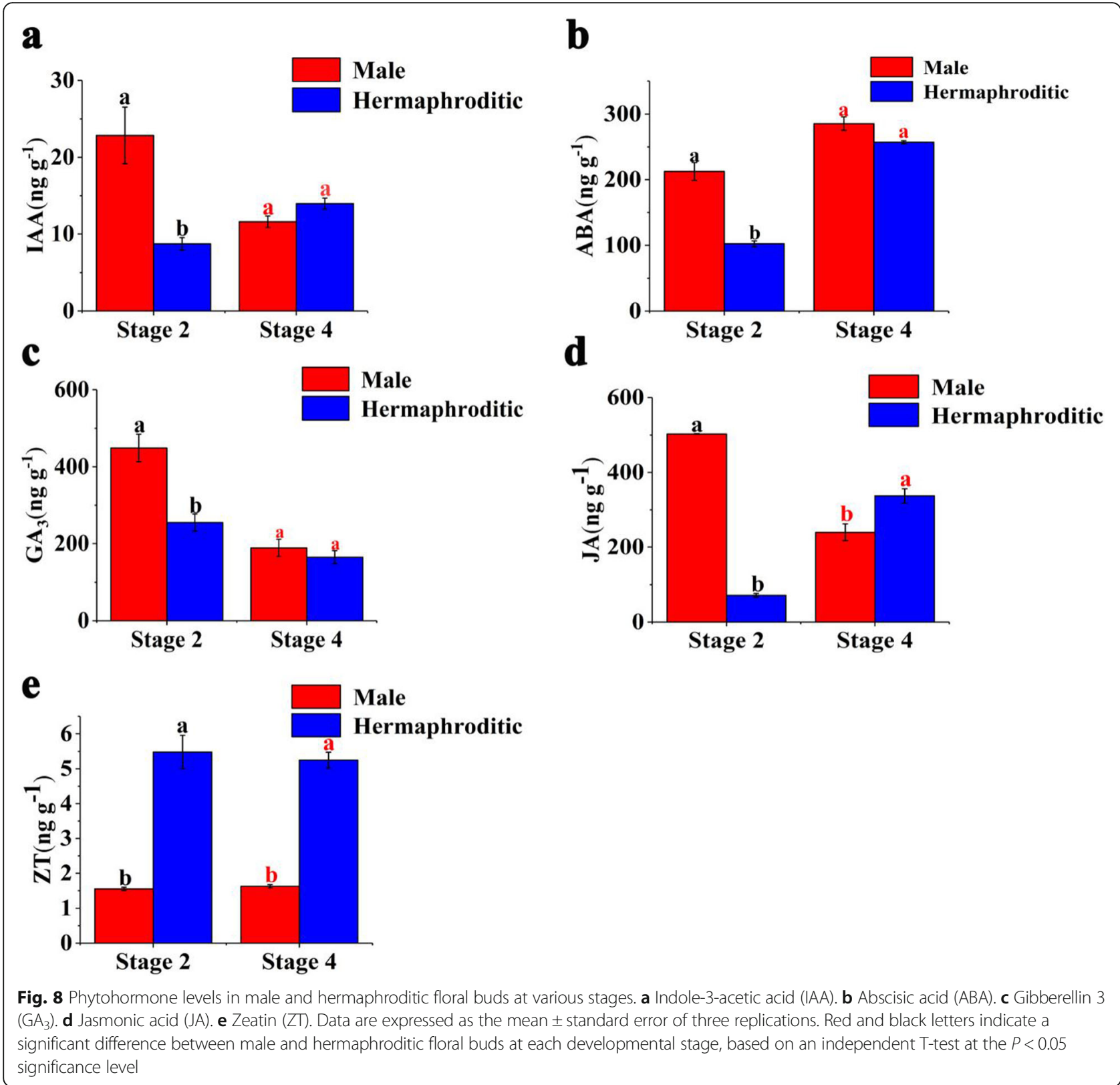

$665,28,377,409,28,193,129$, and 27,702,413 clean reads with lengths of 18-30 nt were generated (Additional file 7: Table S6). The miRNA length distributions were similar among libraries, and 24-nt RNAs were the most abundant (Fig. 13). Fifty-two conserved miRNAs in 20 miRNA families and 81 predicted novel miRNAs were found in the 12 small RNA libraries (Additional file 8: Table S7).

We compared the miRNA expression between the male and hermaphroditic floral buds at stages 2 and 4 in order to detect differentially expressed miRNA (DEMs). Nineteen differentially expressed miRNAs (including 12 conserved and seven novel miRNAs) were identified.
Compared with the hermaphroditic floral buds at stage 2, 7 DEMs were upregulated and 7 were downregulated in the male floral buds. At stage 4, 3 DEMs were upregulated and seven were downregulated in the male floral buds (Table 2).

\section{DEG and DEM correlations}

To clarify the functional miRNA-mRNA interactions, we sought cognate mRNA targets for the DEMs and their predicted target lists using psRobot, TAPIR, and TargetFinder. There were nine and five miRNA-mRNA pairs at stages 2 and 4, respectively (Table 3 ). 
a

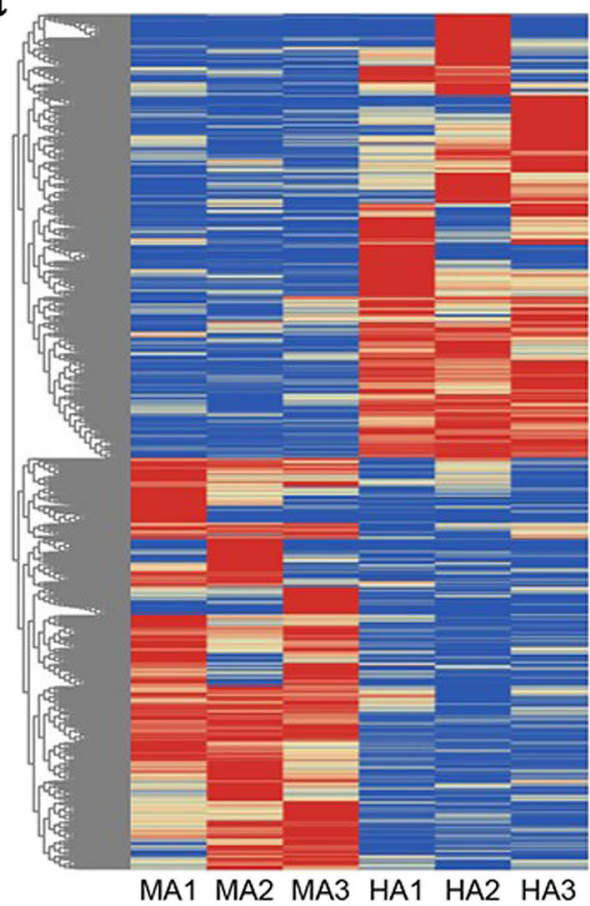

b

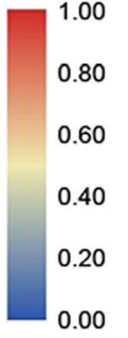

Fig. 9 Heat map of clustered DEGs at stages 2 (a) and 4 (b). The original expression values of the DEG FPKM (fragments per kilobase per million) were normalized by Z-score

\section{DEG and DEM validation by RT-qPCR}

Ten DEGs and seven DEMs at stage 2 and six DEGs and five DEMs at stage 4 were selected to validate transcriptome data accuracy by RT-qPCR. The expression patterns of these genes and their miRNAs were consistent with the RNA-seq and small RNA-seq results. Thus, our sequencing data were reliable (Fig. 14).

\section{Discussion}

Unisexual flowers evolved from hermaphroditic flowers [22]. However, the development process of unisexual flowers is different among different plant species. In some species, the flowers are initially hermaphroditic, and subsequent present with degeneration of the pistil or stamen primordia results in the formation of unisexual flowers. This mechanism was observed in Silene latifolia [23] and D. kaki cultivar 'Zenjimaru' [6]. In another development process, sex differentiation of pistils and carpels proceeds normally and there is no abortion of inappropriate sex organs. This mechanism was observed in Cannabis sativa and Populus deltoides [24]. Here, all floral buds on both sides of the three-flower cyme of 'Longyanyeshi 1' persimmon underwent an initial hermaphroditic period. The pistil primordia of the lateral two floral buds were then arrested and formed male flowers during the microspore mother cell period. In contrast, the pistil and stamen of the central flowers developed normally and formed hermaphroditic flowers. The critical time point for pistil primordia abortion in the male flowers of andromonoecious persimmon coincided with that of a monoecious persimmon reported in a previous study [6].

$O G I$ and $M e G I$ are the key regulators of persimmon sex differentiation. $O G I$ and $M e G I$ promoter methylations regulate $M e G I$ expression in androecious $D$. lotus and monoecious $D$. kaki, respectively. High expression of MeGI promotes female flower development and inhibits male flower development in persimmon [4, 5]. In this study, the expression levels of $O G I$ at stages 2 and 4 were higher in the male floral buds than they were in the hermaphroditic floral buds. However, there were no significant differences between the male and hermaphroditic floral buds at stages 2 and 4 in terms of their MeGI expression levels. Thus, in addition to the OGI/MeGI system, novel regulatory mechanisms may be underlying sex differentiation in andromonoecious persimmon in addition to the OGI/MeGI system. Thus, we performed phytohormone assays and mRNA and small RNA transcriptome analyses of male and hermaphroditic floral buds of the andromonoecious persimmon 'Longyanyeshi 1'.

Phytohormones are important flower development regulators in many plant species [4] and their effects on sex differentiation are widely known [25]. Cytokinins promote female flower development in certain plant 


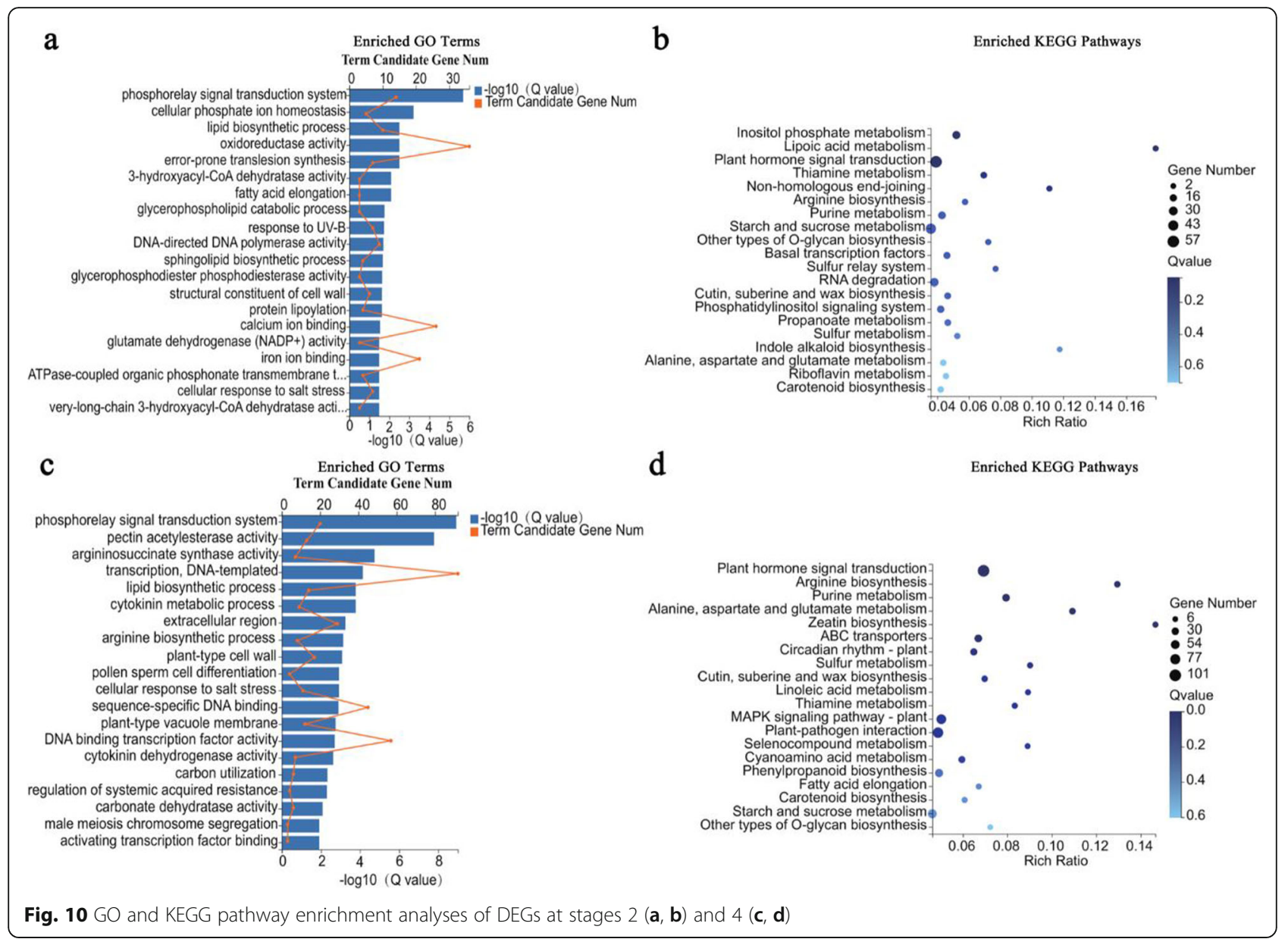

species. Exogenous cytokinins transform male Vitis spp. flowers into hermaphroditic flowers [26]. Genotypically male mercury flowers acquire feminine characteristics after cytokinin treatment [27]. In Actinidia spp., exogenous cytokinin application partially restored gynoecium development in male flowers [28]. In this study, the ZT levels at stage 2 and 4 were higher in hermaphroditic floral buds than in male floral buds, and $A H P, A-A R R$,
B-ARR, CYP735A, and CRE1 genes, which are involved in cytokinin biosynthesis and signaling for regulating flower growth and development [29-35], were differentially expressed at both stages, which indicated that high ZT levels can promote the development of hermaphroditic floral buds at stage 2 and 4, and that these genes may offer excellent candidates in the sex differentiation of 'Longyanyeshi 1'.

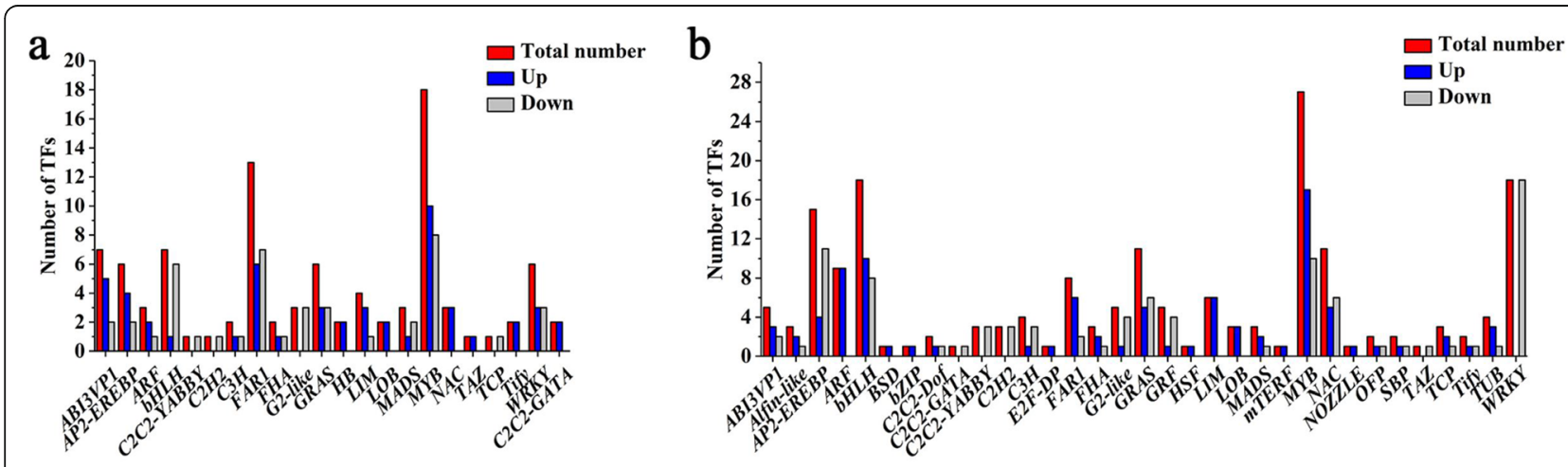

Fig. 11 Numbers of differentially expressed TFs at stages 2 (a) and 4 (b) 


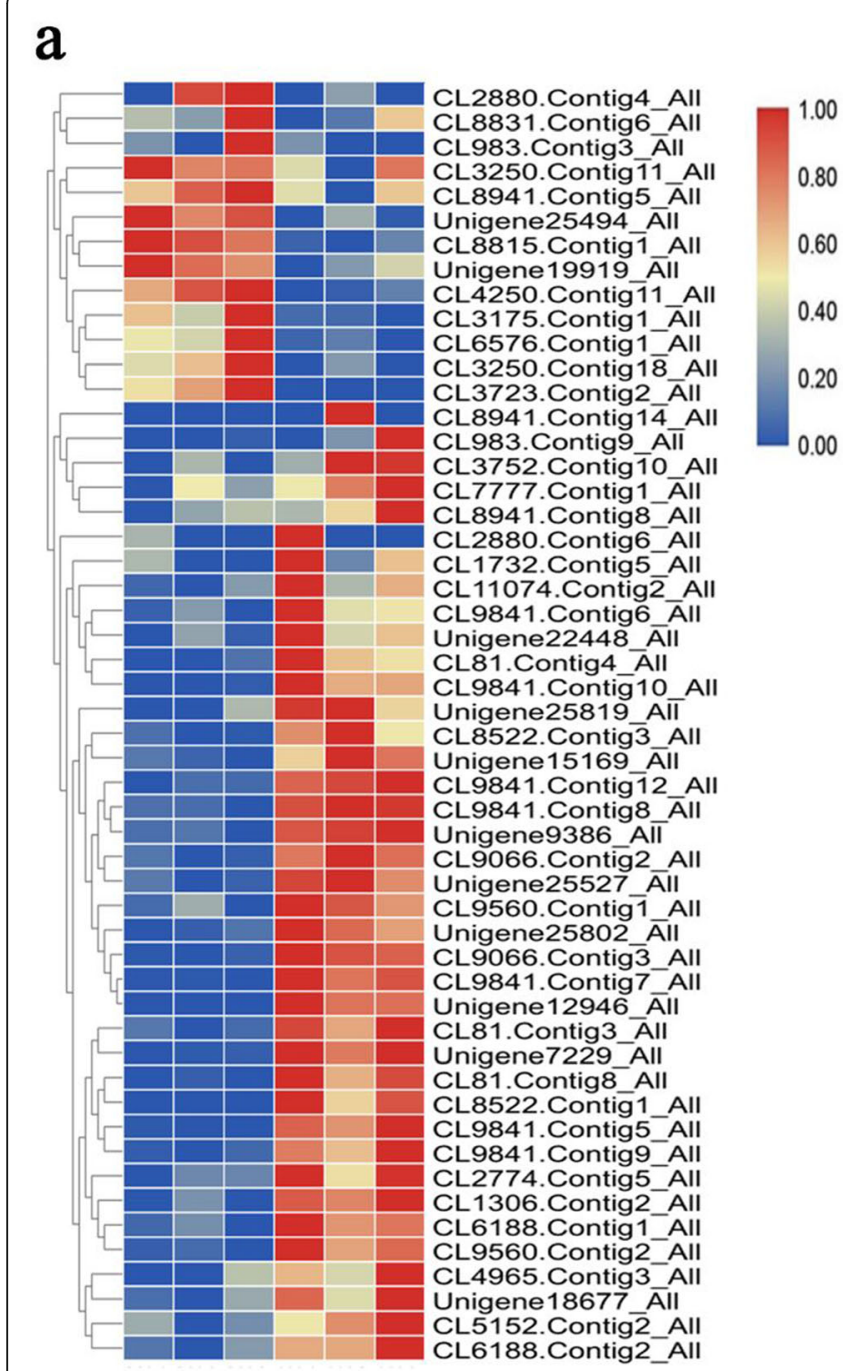

MA1 MA2 MA3 HA1 HA2 HA3 b

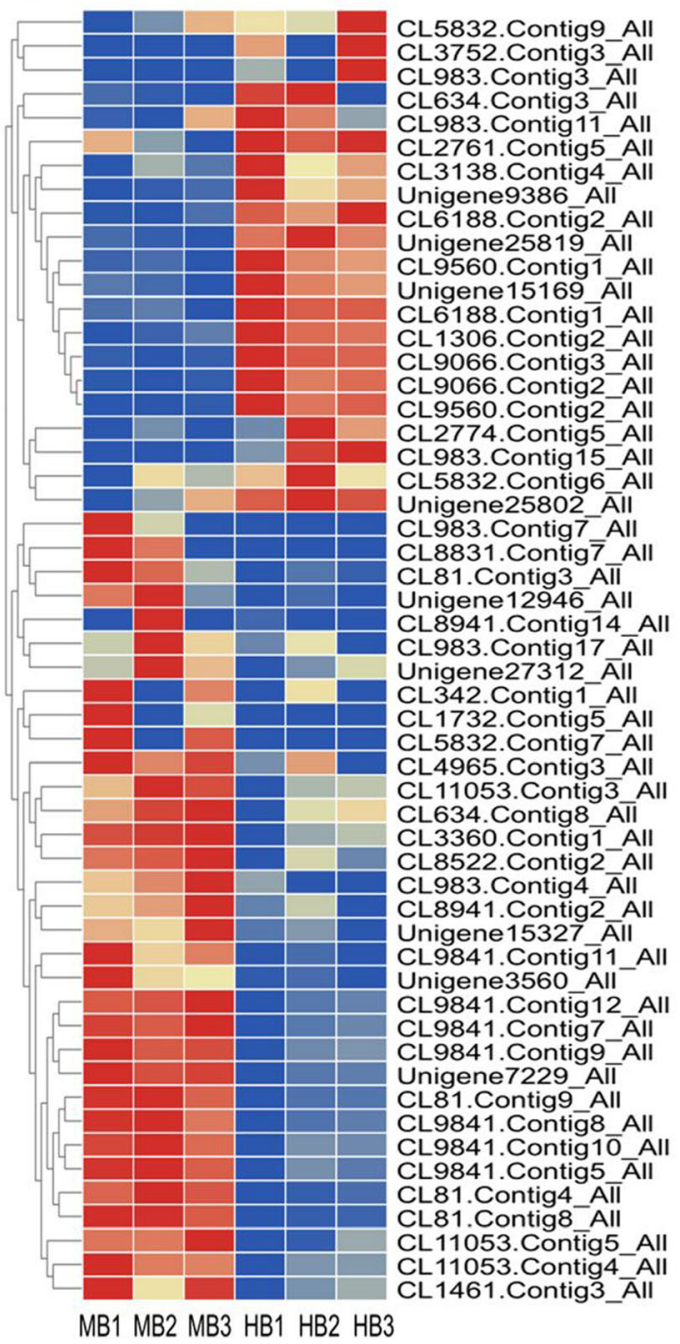

Fig. 12 Heat map of DEGs related to phytohormone biosynthesis and signaling pathways at stages 2 (a) and 4 (b). The original expression values of the DEG FPKM (fragments per kilobase per million) were normalized by Z-score

Jasmonate can participate in root growth, senescence, and reproductive organ formation [36]. Previous studies have shown that jasmonate determines male identity in maize tassel [37]. Mutants defective in jasmonate synthesis or signaling transduction are male-sterile [38]. In this study, the JA levels at stage 2 were higher in male floral buds than in hermaphroditic floral buds, but the opposite trend was observed at stage 4. Furthermore, JAZ, COI1, and $M Y C 2$ genes, which play a central role in JA signaling $[39,40]$, were differentially expressed at stage 2 or 4 , suggesting that JA played different roles in andromonoecious persimmon sex differentiation at different development stages, and that high JA levels were beneficial to the development of male floral buds at stage 2 , whereas they were

Table 1 DEGs related to PCD at stage 4

\begin{tabular}{llll}
\hline Genes ID & log2FC (MA/HA) & Q value & Nr Description \\
\hline CL10736.Contig5_All & 2.180758613 & 0.00082578 & Metacaspase-1-like \\
CL1552.Contig4_All & 2.456003575 & $2.35 E-06$ & Metacaspase-1-like \\
CL1552.Contig9_All & -4.740082502 & 0.000780007 & Putative metacaspase family protein \\
CL1552.Contig12_All & -2.282189273 & $1.81 E-53$ & Metacaspase-1-like \\
CL1552.Contig16_All & 1.495553765 & $1.39 E-05$ & Metacaspase-1-like \\
\hline
\end{tabular}




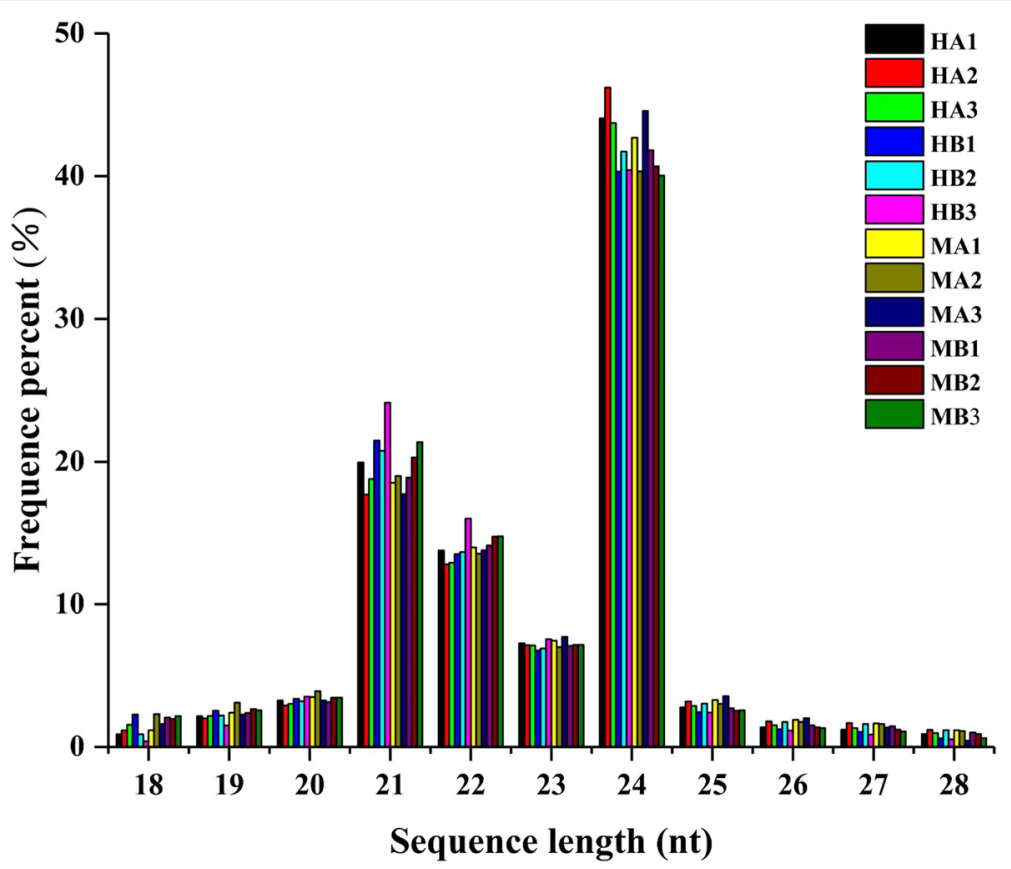

Fig. 13 Small RNA length distribution and abundance in 12 libraries. X-axis, length of small RNA distribution; Y-axis, corresponding percentage of raw reads

more beneficial to the development of hermaphroditic floral buds at stage 4. And JA signaling transduction genes may have important roles in andromonoecious persimmon sex differentiation.

Auxin masculinizes numerous plant species, such as Humulus lupulus [41] and Mercurialis annua [42]. Our results were in accordance with previous reports that the IAA levels at stage 2 were higher in male floral buds than in hermaphroditic floral buds, which indicated that high IAA levels were contributed to the formation of male floral buds at this stage. Aux/IAA are early auxin response proteins that participate in auxin signaling by interacting with ARF proteins as transcriptional repressors [43]. Among auxin signaling-related genes, $A u x / I A A$ and $A R F s$ were highly expressed in male floral buds at stage 2, suggesting that these genes may be important candidates in the sex differentiation of 'Longyanyeshi 1 '.

Gibberellins influence male expression in different plant species $[44,45]$. The application of gibberellin inhibitors induces pistil development in male papaya [24]. In this study, the $\mathrm{GA}_{3}$ levels at stage 2 were higher in male floral buds than in hermaphroditic floral buds, Furthermore, DELLA genes, which are nucleus-localized transcription regulators that participate in GA signaling and flower development [46], were identified at this stage, indicating that high $\mathrm{GA}_{3}$ levels were essential for the development of male floral buds at stage 2 , and DELLA genes may participate in the GA signaling to regulate the sex differentiation of 'Longyanyeshi 1 '.
Abscisic acid regulates multiple flower development processes [45] including initiation, differentiation, and senescence. In this study, the ABA levels at stage 2 were higher in male floral buds than in hermaphroditic floral buds, which indicated that high ABA levels may play important roles in the development of male floral buds at this stage. $P P 2 C$ has a key role in ABA signaling, and it was upregulated in male floral buds at stage 2, which was inconsistent with the result of a previous study that showed that $P P 2 C$ is a negative regulator of $A B A$ responses [47].

Ethylene is thought to be vital for plant sex differentiation [48]. It has a major role in female phenotypic expression [8]. The $A C O$ genes are critical for ethylene biosynthesis [49]. Here, $A C O$ was upregulated in the hermaphroditic floral buds at stages 2 and 4 . Therefore, ethylene may promote pistil development in hermaphroditic 'Longyanyeshi 1 ' floral buds.

TFs are crucial for gene networks. Members of the MYB protein family are flower development regulators [50], and certain MYB TFs are DELLA-responsible GA response genes involved in stamen and pollen maturation [51]. The bHLH and FAR1 TFs participate in light signaling and flowering timing regulation in Arabidopsis [52, 53]. The WRKY TFs have various roles in plant disease resistance, abiotic stress response, nutrient deprivation, senescence, and phytohormone-controlled processes [54]. The transcription factor MADS controls sex differentiation by regulating reproductive organ development in plants [55- 
Table 2 DEMs at stages 2 and 4

\begin{tabular}{|c|c|c|c|c|}
\hline Stage & miRNA name & miRNA sequence & $\begin{array}{l}\text { log2Ratio } \\
\text { (MA/HA) }\end{array}$ & $\mathrm{Q}$ value \\
\hline \multirow[t]{14}{*}{ Stage 2} & miR157a-5p & TTGACAGAAGATAGAGAGCAC & -1.292327831 & 0 \\
\hline & miR157d & TGACAGAAGATAGAGAGCAC & -1.611290674 & $5.20 \mathrm{E}-10$ \\
\hline & $\operatorname{miR} 157 d-3 p$ & GCTCTCTATGCTTCTGTCATC & -1.16042311 & 0 \\
\hline & miR166e & GGACCAGGCTTCATTCCCC & 2.536704288 & 0 \\
\hline & miR169b-5p & CAGCCAAGGATGACTTGCCGG & 1.126376469 & $2.38 \mathrm{E}-125$ \\
\hline & miR169e_3 & AGCCAAGGATGACTTGCCGG & -5.573054385 & 0 \\
\hline & miR169v_1 & CAGCCAAGGATGACTTGCC & 5.253333465 & 0 \\
\hline & miR319_1 & TTGGACTGAAGGGAGCTCC & 2.431345847 & $2.35 E-185$ \\
\hline & miR319a & CTTGGACTGAAGGGAGCTCC & -3.391424127 & 1.93E-161 \\
\hline & miR390e & AGCTCAGGAGGGATAGCGCC & -1.188527882 & $1.25 \mathrm{E}-23$ \\
\hline & novel_mir27 & GCTTACTTCGGAGCGGGAGTACTCGA & -4.45853832 & 0.00051746 \\
\hline & novel_mir30 & CATCGGTGGCCATAGAAAAGGAAAAAG & 4.585855796 & 0.00028378 \\
\hline & novel_mir35 & TAAGGTGAAAGGTGTGTGTTT & 4.701333014 & 0.00015746 \\
\hline & novel_mir63 & AATTTAATATCATGTGGGCCGATG & 4.701333014 & 0.00015746 \\
\hline \multirow[t]{10}{*}{ Stage 4} & miR166e & GGACCAGGCTTCATTCCCC & -1.397911379 & 0 \\
\hline & miR166m_2 & CGGACCAGGCTTCATTCCCC & 1.361643651 & 0 \\
\hline & miR169e_3 & AGCCAAGGATGACTTGCCGG & -6.747470965 & 0 \\
\hline & miR169v_1 & CAGCCAAGGATGACTTGCC & 7.035071502 & 0 \\
\hline & miR171a_3 & TGATTGAGCCGTGCCAATAT & -1.01935132 & $1.56 \mathrm{E}-24$ \\
\hline & miR319a & CTTGGACTGAAGGGAGCTCC & -1.190745132 & $7.98 \mathrm{E}-26$ \\
\hline & miR390e & AGCTCAGGAGGGATAGCGCC & -1.465393915 & $6.28 \mathrm{E}-46$ \\
\hline & novel_mir1 & GTGGATTGGACATTTAGTTTGC & -4.57059320 & 0.0005949 \\
\hline & novel_mir25 & CACAATGACACGCCAACGGCGCA & 1.146226258 & $1.55 \mathrm{E}-53$ \\
\hline & novel_mir46 & AACCCATTGATTCCCAAATTT & -5.509192658 & $1.02 \mathrm{E}-06$ \\
\hline
\end{tabular}

Table 3 MiRNA-mRNA pairs at stages 2 and 4

\begin{tabular}{lllll}
\hline Stage & miRNA & Target gene & log2FC (MA/HA) & Nr Description \\
\hline Stage 2 & miR157d & CL2363.Contig6_All & -1.262814541 & Vacuolar amino acid transporter 1 \\
& miR157d & Unigene22044_All & -5.102609588 & Hypothetical protein VITISV_025837 \\
& miR166e & CL1331.Contig8_All & 1.397213153 & Phabulosa \\
& miR169e_3 & CL1032.Contig1_All & 1.094476454 & Nuclear transcription factor Y subunit A-1-like isoform X1 \\
& miR169e_3 & CL1314.Contig2_All & 6.041229196 & Serine/threonine-protein kinase ppk15 isoform X2 \\
& miR169v_1 & CL1032.Contig1_All & 1.094476454 & Nuclear transcription factor Y subunit A-1-like isoform X1 \\
& miR169v_1 & Unigene33268_All & -2.028567844 & 26S proteasome non-ATPase regulatory subunit 2 homolog A \\
& miR319_1 & CL1678.Contig7_All & -3.102755082 & Transcription factor TCP2 \\
Stage 4 & miR319a & CL1678.Contig7_All & -3.102755082 & Transcription factor TCP2 \\
& miR169e_3 & CL1314.Contig19_All & 1.300124884 & Probable serine/threonine-protein kinase dyrk1 \\
& miR169e_3 & CL1314.Contig20_All & -1.990939687 & Dual specificity protein kinase CLK1 isoform X1 \\
& miR319a & CL1678.Contig7_All & 2.61840453 & Transcription factor TCP2 \\
& miR390e & CL3825.Contig3_All & 2.120159009 & Probable LRR receptor-like serine/threonine-protein kinase At1g63430 \\
& novel_mir1 & CL1148.Contig10_All & -1.354299186 & Pheophytinase, chloroplastic isoform X2 \\
\hline
\end{tabular}




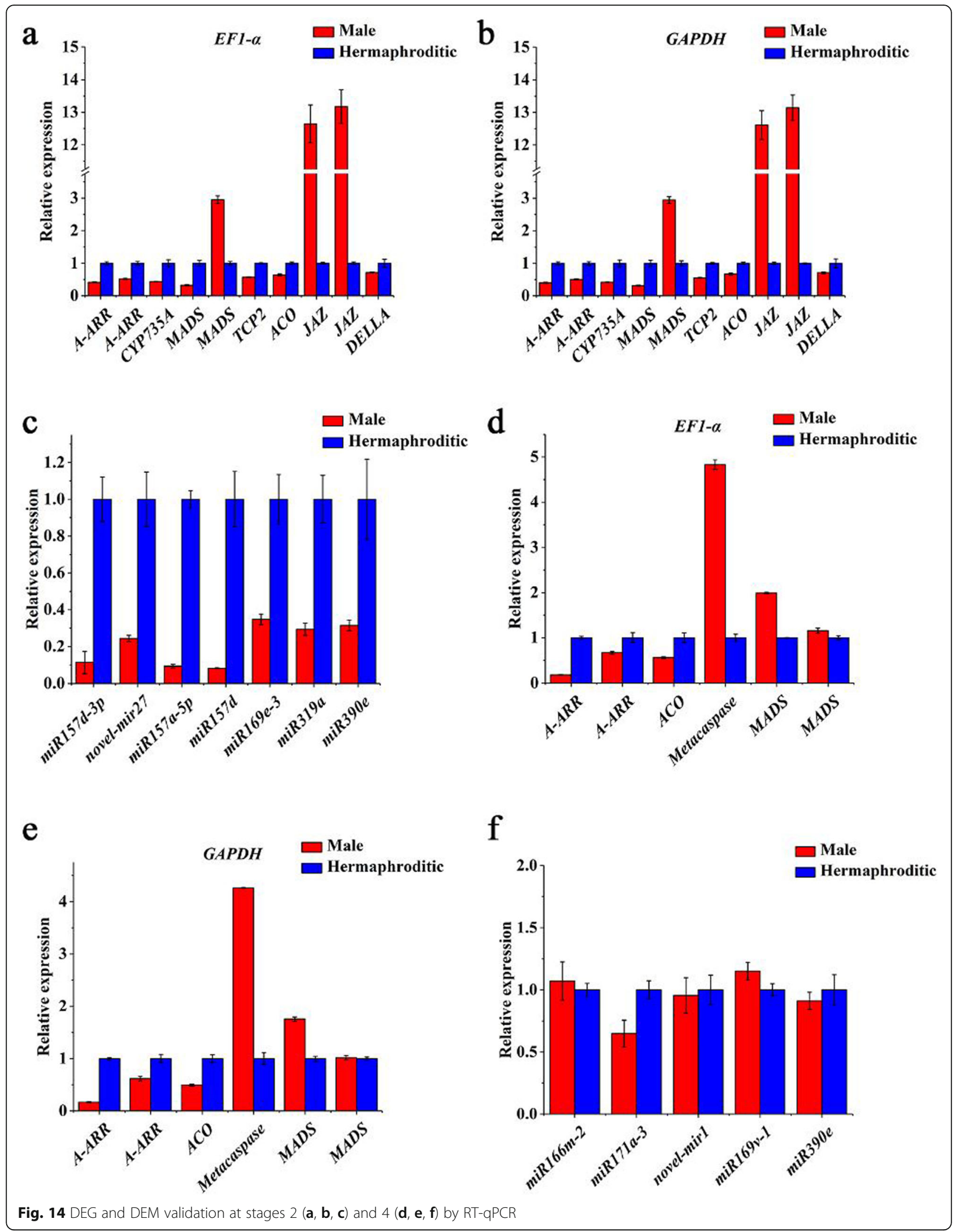


59]. In this study, $18 M Y B, 13$ FAR 1,7 bHLH, and 3 $M A D S$ TFs were differentially expressed at stage 2 , and 27 $M Y B, 18 b H L H, 18 W R K Y$, and 3 MADS TFs were differentially expressed at stage 4 . These TFs may have performed certain sex differentiation-related functions in 'Longyanyeshi 1' floral buds.

Programmed cell death (PCD) is a normal part of a multicellular organism's life. It is active and orderly and may occur at various developmental stages. In 'Zenjimaru' (D. kaki), abortion of inappropriate pistil and stamen primordia was closely associated with PCD [21]. Members of the metacaspase family might induce PCD [60]. Here, five genes belonging to the metacaspase family were identified at stage 4 . Metacaspases might be implicated in male floral bud development, as they suppress pistil primordia.

MiRNAs regulate various biological and metabolic processes associated with plant growth and development such as signal transduction and responses to biotic and abiotic stress [61]. In our study, miR169v_1 and miR169e_3 were significantly upregulated and downregulated, respectively, in male floral buds at stage 2. Their target nuclear transcription factor Y subunit A-1-like isoform X1 (NFYA1), which performs redundant roles in male gametophyte development, embryogenesis, seed development, and postgerminative growth [62], was upregulated at this stage. The 26S proteasome non-ATPase regulatory subunit 2 homolog A (RPN1A), which is the target of miR169v_1 and downregulates ABA signaling transduction [63], was markedly downregulated at this stage. Thus, miR169v_1 plays an important part in male floral bud development at stage 2 as it downregulates RPN1A and controls phytohormone biosynthesis. Both miR169v_1 and miR169e_3 have key functions in the regulation of sex differentiation in andromonoecious persimmon because they target RPN1A or NFYA1. Here, miR319_1 was downregulated in the hermaphroditic floral buds at stage 2, whereas miR319a was upregulated in them at stages 2 and 4 . Their target transcription factor TCP2 (TCP2) is involved in embryonic growth, floral organogenesis, pollen development, diurnal rhythm, and phytohormone signal transduction [64]. TCP2 was upregulated at stage 2 and downregulated at stage 4 in the hermaphroditic floral buds. As miR319_1 and miR319a target TCP2, they may regulate floral bud sex differentiation in andromonoecious persimmon.

The current results suggest that exogenous phytohormone spraying may be used to artificially regulate the conversion of male flowers to hermaphroditic flowers in persimmon, which will be valuable in crossbreeding. In addition, the selected candidate genes and miRNAs can be used for subsequent functional verification and construction of a molecular regulatory network for sex differentiation of andromonoecious persimmon.

\section{Conclusion}

To our knowledge, the present study is the first to describe the sex differentiation mechanism in the floral buds of the andromonoecious persimmon 'Longyanyeshi 1 '. The absence of ovary primordia and ovules in the carpels at stage 2 and the abortion of carpels at stage 4 distinguished the male from the hermaphroditic floral buds. Thus, stages 2 and 4 are critical morphological periods for sex differentiation of 'Longyanyeshi 1'. Differential expression analysis of OGI and MeGI showed that a novel supplementary mechanism may determine andromonoecious persimmon sexuality. The upregulation of IAA, $\mathrm{ABA}, \mathrm{GA}_{3}$, and JA at stage 2 may promote male floral bud differentiation, whereas the upregulation of JA at stage 4 and ZT at stages 2 and 4 may promote hermaphroditic floral bud differentiation. Ninety-five and 183 TFs were differentially expressed at stages 2 and 4, respectively. $M Y B$, FAR1, bHLH, WRKY, and MADS might play important roles in persimmon floral bud sex differentiation. Fifty-two and 54 DEGs at stages 2 and 4, respectively, participated in phytohormone biosynthesis and signaling pathways to regulate persimmon floral bud sex differentiation. Five metacaspases might perform vital functions in 'Longyanyeshi 1' male floral bud development by suppressing pistil primordia at stage 4 . Integrated miRNA-mRNA analyses showed that several miRNAs involved in phytohormone biosynthesis and signaling pathways and floral organogenesis could regulate floral bud sex differentiation. This study laid an empirical foundation for ongoing investigations of floral bud sex differentiation in andromonoecious persimmon.

\section{Methods \\ Plant materials}

The 'Longyanyeshi 1' persimmon (Diospyros kaki) tree was a six-year-old seedling growing in Yuanyang County, Henan Province, China $\left(34^{\circ} 55^{\prime} 18^{\prime \prime} \sim 34^{\circ} 56^{\prime} 27^{\prime \prime} \mathrm{N}\right.$, $\left.113^{\circ} 46^{\prime} 14^{\prime \prime} \sim 113^{\circ} 47^{\prime} 35^{\prime \prime} \mathrm{E}\right)$ and it was cultivated from the seed of a wild D. kaki obtained in Longyan City, Fujian Province, Southeast China. The plant was an andromonoecious persimmon found by $\mathrm{Fu}$ and her research team [20]. All developmental stages of floral buds were proved to have stable horticultural characteristics during 3 years of field observation. The male and hermaphroditic floral buds were randomly collected every $3 \mathrm{~d}$ between March 28, 2018 and April 20, 2018 from the tree. Certain samples were fixed in FAA (formalin: glacial acetic acid: $50 \%(\mathrm{v} / \mathrm{v})$ alcohol = 8:5:87, v/v). Others were immediately frozen in liquid nitrogen and stored at $-80^{\circ} \mathrm{C}$ until phytohormone and RNA extraction.

\section{Paraffin section}

Male and hermaphroditic floral buds fixed in FAA for $24 \mathrm{~h}$ were dehydrated in a graded ethanol series. They were then embedded in paraffin heated from 40 to $60^{\circ} \mathrm{C}$ at an increment of $3{ }^{\circ} \mathrm{C}$ per $15 \mathrm{~min}$. The samples were 
then immersed thrice in $60^{\circ} \mathrm{C}$ paraffin for $2 \mathrm{~h}$ each time. Sections $(5 \mu \mathrm{m}$ thick) were prepared with a Leica RM2265 microtome (Leica Microsystems, Nussloch, Germany) and mounted on clean glass slides. The sections were deparaffinized and rehydrated in a graded $x y-$ lol and ethanol series and stained overnight with hematoxylin. After staining with $1 \%$ eosin for $20 \mathrm{~s}$, the sections were dehydrated in a graded ethanol and xylol series. The microslides were dried and mounted with cover slips and the stained sections were observed and photographed under a light microscope (Olympus, Tokyo, Japan).

\section{Phytohormone quantification by HPLC-ESI-MS/MS}

Samples each weighing $\sim 50 \mathrm{mg}(\mathrm{FW})$ were transferred to 2-mL centrifuge tubes. The extraction and purification steps required for the determination of IAA, ABA, $\mathrm{GA}_{3}, \mathrm{ZT}$, and JA were conducted according to the methods described by Pan [65].

High-performance liquid chromatography-electrospray ionization tandem-mass spectrometry (HPLC-ESI-MS/ MS) in multiple-reaction monitoring (MRM) mode was used to quantitate the endogenous phytohormone levels. The HPLC-ESI-MS/MS consisted of an Agilent 1260 HPLC system (Agilent Technologies, Santa Clara, CA, USA) and an $A B$ Qtrap 5500 triple quadrupole mass spectrometer (AB Sciex LLC, Framingham, MA, USA) with an electrospray ionization source. Samples were injected into an Agilent SB-C18 column $(50 \mathrm{~mm} \times 4.6$ $\mathrm{mm}, 1.8 \mu \mathrm{m}$; Agilent Technologies, Santa Clara, CA, USA) and separated at a flow rate of $0.8 \mathrm{~mL} \mathrm{~min}^{-1}$ with following mobile phases: acetonitrile (A) and distilled water with $0.1 \%$ acetic acid (B) for IAA, ABA, GA, JA; and acetonitrile (A) and distilled water (B) for ZT. The HPLC gradient program and the multiple reaction monitoring (MRM) conditions used to quantify the phytohormones were adapted from Pan [65]. The injection volumes were $5.0 \mu \mathrm{L}$ for IAA, $\mathrm{ABA}, \mathrm{GA}_{3}$, and $\mathrm{JA}$, and $1.0 \mu \mathrm{L}$ for $\mathrm{ZT}$.

Data acquisition and processing were performed in $A B$ SCIEX Analyst v. 1.7 (AB Sciex LLC, Framingham, MA, USA). The content of each phytohormone was calculated as follows:

phytohormone content $=$ (peak area of authentic phytohormone $\times$ amount of corresponding internal standard) / (peak area of corresponding internal standard $x$ fresh weight of each sample).

\section{Total RNA extraction}

Total RNA was isolated with TRIzol Reagent (Invitrogen, Carlsbad, CA, USA). RNA quality was tested with a Nano Drop 2000 spectrophotometer (Thermo Fisher Scientific, Wilmington, DE, USA) at $260 \mathrm{~nm} / 280 \mathrm{~nm}$ (ratio $>2.0$ ) and an Agilent 2100 bioanalyzer (Thermo Fisher Scientific, Waltham, MA, USA).

\section{Transcriptome sequencing and analysis}

Sequencing libraries for mRNA were generated with an Illumina TruSeq RNA Sample Preparation Kit (Illumina, San Diego, CA, USA) following the manufacturer's recommendations. The library was sequenced on a BGIseq500 platform (BGI Group, Shenzhen, Guangdong, China) and paired-end reads were generated. To obtain clean reads, the raw reads were filtered by removing low-quality reads and those containing adaptors and poly-N. Clean reads were assembled with Trinity v. 2.0.6 for de novo transcriptome assembly [66]. Unique genes were obtained with Tgicl v. 2.0.6 [67].

BLAST in the NR, NT, Swissprot, KEGG, KOG, Pfam, and GO databases was used for gene functional annotation. DEseq2 was used to detect differential mRNA expression (DEGs) (fold change $\geq 2 ; \mathrm{Q} \leq 0.001$ ) [68]. Phyper was performed for the GO and KEGG enrichment analyses $(\mathrm{Q} \leq 0.05)$.

\section{Small RNA sequencing and analysis}

Sequencing libraries for small RNAs were generated with an Illumina TruSeq Small RNA Preparation Kit (Illumina, San Diego, CA, USA) following the manufacturer's recommendations. The libraries were sequenced on a BGIseq500 platform (BGI Group, Shenzhen, Guangdong, China). After removing low-quality reads, the clean reads were mapped to the sRNA database (miRbase, siRNA, and snoRNA) with Bowtie v. 2.2.2.2.9 [69]. The miRA software was used to predict novel miRNA [70]. TAPIR, psRobot, and TargetFinder were used to predict target genes of miRNAs [71-73]. DEM analysis was performed using the DEGseq $(\mathrm{Q} \leq 0.001$; absolute value of $\log 2$ Ratio $\geq 1$ ) [74]. To annotate gene functions, all target genes were aligned against the KEGG and GO databases. GO and KEGG enrichment analyses of target genes were performed using phyper $(\mathrm{Q} \leq 0.05)$.

To determine the OGI expression level, small RNAs reads were mapped to the D. lotus OGI sequence [75], the MeGI sequence from the D. oleifera genome [76], and the 'Kali' sequence cloned from 'Longyanyeshi 1' persimmon (Fig. 4). Mapping was performed according to the method described by Akagi [5]. Expression levels were recorded as reads per million reads. Three biological replicates were analyzed per sample.

\section{Real-time quantitative polymerase chain reaction (RT- qPCR)}

Total RNA for RNA-Seq and small RNA analysis was reverse-transcribed into cDNA with a TRUE-script 1stStrand cDNA Synthesis Kit (Kemix, Beijing, China) and a Mir- $\mathrm{X}^{\mathrm{Tm}}$ miRNA First-Strand Synthesis Kit (Takara, Dalian, China). The primers were used for RT-qPCR in a 
real-time system. Quantification of DEG and DEM expression was detected with TB Green ${ }^{\mathrm{Tm}}$ Premix Ex Taq ${ }^{\mathrm{mm}}$ II (Tli RNaseH Plus) (Takara, Dalian, China) and a Mir$\mathrm{X}$ miRNA RT-qPCR TB Green Kit (Takara, Dalian, China), respectively. The reaction conditions for the DEGs were $30 \mathrm{~s}$ at $95^{\circ} \mathrm{C}$ followed by 40 cycles of $3 \mathrm{~s}$ at $95^{\circ} \mathrm{C}$ and $30 \mathrm{~s}$ at $60^{\circ} \mathrm{C}$. The reaction conditions for the DEMs were $10 \mathrm{~s}$ at $95^{\circ} \mathrm{C}$ followed by 40 cycles of $5 \mathrm{~s}$ at $95^{\circ} \mathrm{C}$ and $20 \mathrm{~s}$ at $60^{\circ} \mathrm{C}$. Three technical replicates were performed for each mRNA and miRNA sample. EF1- $\alpha$ and GAPDH served as reference genes for mRNA RTqPCR [77]. U6 served as a reference gene for miRNA RT-qPCR. The relative expression values were obtained by the $2^{-\Delta \Delta C t}$ method. The DEG and DEM primers for RT-qPCR are listed in Tables S8 and S9 (Additional file 9: Table S8 and Additional file 10: Table S9).

\begin{abstract}
Abbreviations
ABA: abscisic acid; DEG: differentially expressed gene; DEM: differentially expressed mRNA; ESI: electrospray ionization; FAA: formalin: acetic acid: alcohol; FR: forward repeat; FC: fold change; FPKM: fragments per kilobase per million; FW: fresh weight; $\mathrm{GA}_{3}$ : gibberellic acid; GO: gene ontology; HPLC: high-performance liquid chromatography; IR: inverted repeat; IAA: indole-3-acetic acid; JA: jasmonic acid; KEGG: Kyoto Encyclopedia of Genes and Genomes; MiRNA: microRNA; MRM: multiple-reaction monitoring; MS/MS: tandem mass spectrometry; PCD: programmed cell death; RTQPCR: real time quantitative polymerase chain reaction; TF: transcription factor; UTR: untranslated region; ZT: zeatin
\end{abstract}

\section{Supplementary Information}

The online version contains supplementary material available at https://doi. org/10.1186/s12864-021-07514-4.

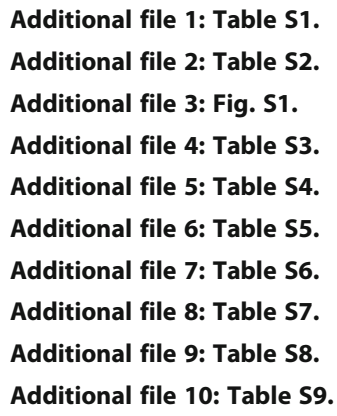

\section{Acknowledgements}

We thank Prof. Ryutaro Tao and Dr. Soichiro Nishiyama of the Graduate School of Agriculture, Kyoto University for their assistance in data analysis.

\section{Authors' contributions}

JMF and PS designed experiments. WJH, YJS, and SFD analyzed the sequencing data. YNM performed RT-qPCR experiment. HWL and LYW written the manuscript. All authors read and approved the manuscript.

\section{Funding}

This research was supported by the National Key R\&D Program of China (2019YFD1000600) and the Fundamental Research Funds for the Central Non-profit Research Institution of CAF (CAFYBB2017ZA005). The funders provided the financial support to the research, but had no role in the design of the study, analysis, interpretations of data and in writing the manuscript.

\section{Availability of data and materials}

The materials of this study were provided by the Non-timber Forest Research and Development Center, Chinese Academy of Forestry. The raw sequencing data have submitted to the NCBI SRA database (PRJNA647029).

\section{Declarations}

Ethics approval and consent to participate

All experiment materials were collected according to the IUCN Policy Statement on Research Involving Species at Risk of Extinctionand the Convention on the Trade in Endangered Species of Wild Fauna and Flora. This study was also approved by the Ethics Committee for Non-timber Forest Research and Development Center, Chinese Academy of Forestry.

\section{Consent for publication}

Not applicable.

\section{Competing interests}

We declare that the research was conducted in the absence of any commercial or financial relationships that could be a potential conflict of interest.

\section{Author details}

${ }^{1}$ Key Laboratory of Non-timber Forest Germplasm Enhancement \& Utilization of State Administration of Forestry and Grassland, No. 3 Weiwu Road, Jinshui District, Zhengzhou 450003, China. ${ }^{2}$ Non-timber Forest Research and Development Center, Chinese Academy of Forestry, No. 3 Weiwu Road, Jinshui District, Zhengzhou 450003, China. ${ }^{3}$ National Innovation Alliance of Persimmon Industry, No. 3 Weiwu Road, Jinshui District, Zhengzhou 450003, China. ${ }^{4}$ Research Institute of Forestry, Chinese Academy of Forestry, Beijing 100091, China.

Received: 3 August 2020 Accepted: 8 March 2021

Published online: 23 March 2021

\section{References}

1. Luo ZR, Wang RZ. Persimmon in China: domestication and traditional utilizations of genetic resources. Adv Hort Sci. 2008;22:239-43.

2. Wang LY, Li HW, Suo YJ, Han WJ, Diao SF, Mai YN, Sun P, Li FD, Fu JM. Effects of plant growth regulators, soil moisture contents, and carbon/ nitrogen ratios on sex differentiation in persimmon (Diospyros kaki Thunb.) flowers. J Plant Growth Regul. 2020. https://doi.org/10.1007/s00344-020-101 70-9.

3. Lewis D. The evolution of sex in flowering plants. Biol Rev. 1942;17(1):46-67. https://doi.org/10.1111/j.1469-185X.1942.tb00431.x.

4. Akagi T, Henry IM, Tao R, Comail L. A Y-chromosome-encoded small RNA acts as a sex determinant in persimmons. Science. 2014;346(6209):646-50. https://doi.org/10.1126/science.1257225

5. Akagi T, Henry IM, Kawai T, Comail L, Tao R. Epigenetic regulation of the sex determination gene MeGl in polyploid persimmon. Plant Cell. 2016;28(12): 2905-15. https://doi.org/10.1105/tpc.16.00532.

6. Li JR, Sun P, Han WJ, Li FD, Fu JM, Diao SF. Morphological key period study on floral sex differentiation in pollination-constant and non-astringent persimmon 'Zenjimaru'. Acta Hortic Sin. 2016;43(3):451-61.

7. Sun P, Li JR, Du GG, Han WJ, Fu JM, Diao SF, Suo YJ, Zhang Y, Li FD. Endogenous phytohormone profiles in male and female floral buds of the persimmons (Diospyros kaki, Thunb.) during development. Sci Hortic. 2017; 218:213-21. https://doi.org/10.1016/j.scienta.2017.02.022.

8. Jaiswal VS, Kumar A, Lal M. Role of endogenous phytohormones and some macromolecules in regulation of sex differentiation in flowering plants. Proc Plant Sci. 1985;95(6):453-9.

9. Irish EE, Nelson T. Sex determination in monoecious and dioecious plants. Plant Cell. 1989;1(8):737-44. https://doi.org/10.2307/3868981.

10. Acosta IF, Laparra H, Romero SP, Schmelz E, Hamberg M, Mottinger JP, Moreno MA, Dellaporta SL. tasselseed1 is a lipoxygenase affecting jasmonic acid signaling in sex determination of maize. Science. 2009;323(5911):262-5. https://doi.org/10.1126/science.1164645.

11. Anopriyenko OV, Zakian SM. Evolution of mammalian sex chromosomes: cooperation of genetic and epigenetic factors. Russ J Genet. 2004;40(8):82543. https://doi.org/10.1023/B:RUGE.0000039715.32142.0f. 
12. Durand $R$, Durand B. Sexual differentiation in higher plants. Physiol Plant. 1984;60(3):267-74. https://doi.org/10.1111/j.1399-3054.1984.tb06061.x.

13. Chailakhyan MK, Timiriazev KA. Genetic and hormonal regulation of growth, flowering, and sex expression in plants. Am J Bot. 1979;66(6):717-36. https:// doi.org/10.1002/j.1537-2197.1979.tb06276.x.

14. Kumar A, Jaiswal VS. Sex reversal and fruit formation on male plants of Carica Papaya L by ethrel and chlorflurenol. Proc Plant Sci. 1984;93(6):635-41.

15. Wu G, Park MY, Conway SR, Wang JW, Weigel D, Poethig RS. The sequential action of miR156 and miR172 regulates developmental timing in Arabidopsis. Cell. 2009;138(4):750-9. https://doi.org/10.1016/j.cell.2009.06.031.

16. Gandikota M, Birkenbihl RP, Höhmann S, Cardon GH, Saedler H, Huijser P. The miRNA156/157 recognition element in the 3' UTR of the Arabidopsis SBP box gene SPL3 prevents early flowering by translational inhibition in seedlings. Plant J. 2007;49(4):683-93. https://doi.org/10.1111/j.1365-313X.2 006.02983.x.

17. Zhu QH, Helliwell CA. Regulation of flowering time and floral patterning by miR172. J Exp Bot. 2011;62(2):487-95. https://doi.org/10.1093/jxb/erq295.

18. Chuck G, Meeley R, Irish E, Sakai H, Hake S. The maize tasselseed4 microRNA controls sex determination and meristem cell fate by targeting Tasselseed6/ indeterminate spikelet1. Nat Genet. 2007;39(12):1517-21. https://doi.org/10.1 038/ng.2007.20.

19. Banks JA. MicroRNA, sex determination and floral meristem determinacy in maize. Genome Biol. 2008;9(1):204. https://doi.org/10.1186/gb-2008-9-1-204.

20. Li HW, Wang LY, Sun P, Suo YJ, Han WJ, Mai YN, Diao SF, Yuan DY, Fu JM. Cytomorphological observation on development of pistil and stamen of male and hermaphrodite floral buds of Diospyros kaki 'Longyan Yeshi 1'. Acta Hortic Sin. 2019:46(10):1897-906.

21. Wang LY, Li HW, Suo YJ, Han WJ, Diao SF, Mai YN, Sun P, Li FD, Fu JM. Programmed cell death facilitates the formation of unisexual male and female flowers in persimmon (Diospyros kaki Thunb.). Agronomy. 2020;10(2):234

22. Charlesworth D. Plant sex determination and sex chromosomes. Heredity. 2002:88(2):94-101. https://doi.org/10.1038/sj.hdy.6800016.

23. Hardenack S, Ye D, Saedler H, Grant S. Comparison of MADS box gene expression in developing male and female flowers of the dioecious plant white campion. Plant Cell. 1994;6(12):1775-87. https://doi.org/10.1105/tpc. 6.12.1775.

24. Aryal R, Ming R. Sex determination in flowering plants: papaya as a model system. Plant Sci. 2014;217:56-62.

25. Golenberg EM, West NW. Hormonal interactions and gene regulation can link monoecy and environmental plasticity to the evolution of dioecy in plants. Am J Bot. 2013;100(6):1022-37. https://doi.org/10.3732/ajb.1200544.

26. Moore JN. Cytokinin-induced sex conversion in male clones of Vitis species. J Am Soc Hortic Sci. 1970;95:387-93.

27. Louis JP, Durand B. Studies with the dioecious angiosperm Mercurialis annua L. $(2 n=16)$ : correlation between genic and cytoplasmic male sterility, sex segregation and feminizing hormones (cytokinins). Mol Gen Genomics. 1978;165(3):309-22. https://doi.org/10.1007/BF00332532.

28. Akagi T, Henry IM, Ohtani H, Morimoto T, Beppu K, Kataoka I, Tao R. A Yencoded suppressor of feminization arose via lineage-specific duplication of a cytokinin response regulator in kiwifruit. Plant Cell. 2018;30(4):780-95. https://doi.org/10.1105/tpc.17.00787.

29. Hutchison CE, Li J, Argueso C, Gonzalez M, Lee E, Lewis MW, Maxwell BB, Perdue TD, Schaller GE, Alonso JM, Ecker JR, Kieber JJ. The Arabidopsis histidine phosphotransfer proteins are redundant positive regulators of cytokinin signaling. Plant Cell. 2006;18(11):3073-87. https://doi.org/10.1105/ tpc.106.045674.

30. Argyros RD, Mathews DE, Chiang YH, Palmer CM, Thibault DM, Etheridge $\mathrm{N}$, Aaron Argyros D, Mason MG, Kieber JJ, Schaller GE. Type B response regulators of Arabidopsis play key roles in cytokinin signaling and plant development. Plant Cell. 2008;20(8):2102-16. https://doi.org/10.1105/tpc.108. 059584

31. Kiba T, Yamada H, Sato S, Kato T, Tabata S, Yamashino T, Mizuno T. The type-a response regulator, ARR15, acts as a negative regulator in the cytokinin-mediated signal transduction in Arabidopsis thaliana. Plant Cell Physiol. 2003;44(8):868-74. https://doi.org/10.1093/pcp/pcg108.

32. To JPC, Haberer G, Ferreira FJ, Derue're J, Mason MG, Schaller GE, Alonso JM, Ecker JR, Kieber JJ. Type-A Arabidopsis response regulators are partially redundant negative regulators of cytokinin signaling. Plant Cell. 2004;16(3): 658-71

33. Lee DJ, Park JY, Ku SJ, Ha YM, Kim S, Kim MD, Oh MH, Kim J. Genome-wide expression profiling of ARABIDOPSIS RESPONSE REGULATOR 7 (ARR7) overexpression in cytokinin response. Mol Gen Genomics. 2007;277(2):11537. https://doi.org/10.1007/s00438-006-0177-x.

34. Takei K, Yamaya T, Sakakibara H. Arabidopsis CYP735A1 and CYP735A2 encode cytokinin hydroxylases that catalyze the biosynthesis of trans-zeatin. J Biol Chem. 2004;279(40):41866-72. https://doi.org/10.1074/jbc.M406337200.

35. Inoue T, Higuchi M, Hashimoto Y, Seki M, Kobayashi M, Kato T, Tababa S, Shinozaki K, Kakimoto T. Identification of CRE1 as a cytokinin receptor from Arabidopsis. Nature. 2001;409(6823):1060-3. https://doi.org/10.1038/35059117.

36. Floková K, Feussner K, Herrfurth C, Miersch O, Mik V, Tarkowská D, Strnad M, Feussner I, Wasternack C, Nová O. A previously undescribed jasmonate compound in flowering Arabidopsis thaliana-the identification of cis(+)-OPDA-Ile. Phytochemistry. 2016;122:230-7. https://doi.org/10.1016/j. phytochem.2015.11.012

37. Browse J. Jasmonate: preventing the maize tassel from getting in touch with his feminine side. Sci Signal. 2009;2(59):pe9. https://doi.org/10.1126/ scisignal.259pe9.

38. Park JH, Halitschke R, Kim HB, Baldwin IT, Feldmann KA, Feyereisen R. A knock-out mutation in allene oxide synthase results in male sterility and defective wound signal transduction in Arabidopsis due to a block in jasmonic acid biosynthesis. Plant J. 2002;31(1):1-12. https://doi.org/10.1046/ j.1365-313X.2002.01328.x.

39. Chico JM, Chini A, Fonseca S, Solano R. JAZ repressors set the rhythm in jasmonate signaling. Curr Opin Plant Biol. 2008;11(5):486-94. https://doi. org/10.1016/j.pbi.2008.06.003.

40. Browse J. Jasmonate passes muster: a receptor and targets for the defense hormone. Annu Rev Plant Biol. 2009;60(1):183-205. https://doi.org/10.1146/a nnurev.arplant.043008.092007.

41. Heslop-Harrison J. Ultrastructural aspects of differentiation in sporogenous tissue. Symp Soc Exp Biol. 1963;17:315-40.

42. Hamdi S, Teller G, Louis JP. Master regulatory genes, auxin levels, and sexual organogeneses in the dioecious plant Mercurialis annua. Plant Physiol. 1987 85(2):393-9. https://doi.org/10.1104/pp.85.2.393.

43. Li SB, Xie ZZ, Hu CG, Zhang JZ. A review of auxin response factors (ARFs) in plants. Front Plant Sci. 2016;7:47.

44. Chailakhyan MK, Khryanin VN. Effect of growth regulators and role of roots in sex expression in spinach. Planta. 1978;142(2):207-10. https://doi.org/10.1 007/BF00388214.

45. Song Y, Ma K, Ci D, Tian J, Zhang D. Sexual dimorphic floral development in dioecious plants revealed by transcriptome, phytohormone, and DNA methylation analysis in Populus tomentosa. Plant Mol Biol. 2013;83(6):559_ 76. https://doi.org/10.1007/s11103-013-0108-2.

46. Li MZ, An FY, Li WY, Ma MD, Feng Y, Zhang X, Guo HW. DELLA proteins interact with FLC to repress flowering transition. J Integr Plant Biol. 2016; 58(7):642-55. https://doi.org/10.1111/jipb.12451.

47. Ma Y, Szostkiewicz I, Korte A, Moes D, Yang Y, Christmann A, Grill E. Regulators of PP2C phosphatase activity function as abscisic acid sensors. Science. 2009;324(5930):1064-8. https://doi.org/10.1126/science.1172408.

48. Yin T, Quinn JA. Tests of a mechanistic model of one hormone regulating both sexes in Buchloe dactyloides (Poaceae). Am J Bot. 1995;82(6):745-51. https://doi.org/10.1002/j.1537-2197.1995.tb15686.x.

49. Adams DO, Yang SF. Ethylene biosynthesis: identification of 1aminocyclopropane-1-carboxylic acid as an intermediate in the conversion of methionine to ethylene. P Natl Acad Sci USA. 1979;76(1):170-4. https:// doi.org/10.1073/pnas.76.1.170.

50. Vimolmangkang S, Han Y, Wei G, Korban SS. An apple MYB transcription factor, MdMYB3, is involved in regulation of anthocyanin biosynthesis and flower development. BMC Plant Biol. 2013;13(1):176. https://doi.org/10.11 86/1471-2229-13-176.

51. Cheng H, Song S, Xiao L, Soo HM, Cheng Z, Xie D, Peng J. Gibberellin acts through jasmonate to control the expression of MYB21, MYB24, and MYB57 to promote stamen filament growth in Arabidopsis. PLoS Genet. 2009;5(3): e1000440. https://doi.org/10.1371/journal.pgen.1000440.

52. Leivar P, Tepperman JM, Cohn MM, Monte E, Al-Sady B, Erickson E, Quail PH. Dynamic antagonism between phytochromes and PIF family basic helixloop-helix factors induces selective reciprocal responses to light and shade in a rapidly responsive transcriptional network in Arabidopsis. Plant Cell. 2012;24(4):1398-419. https://doi.org/10.1105/tpc.112.095711.

53. Xie YR, Zhou Q, Zhao YP, Li QQ, Liu Y, Ma MD, Wang BB, Shen RX, Zheng ZG, Wang HY. FHY3 and FAR1 integrate light signals with the mir156-spl module-mediated aging pathway to regulate arabidopsis flowering. $\mathrm{Mol}$ Plant. 2020;13(3):483-98. https://doi.org/10.1016/j.molp.2020.01.013. 
54. Rushton PJ, Somssich IE, Ringler P, Shen QJ. WRKY transcription factors. Trends Plant Sci. 2010;15(5):247-58. https://doi.org/10.1016/j.tplants.2010.02.006.

55. Weigel D, Meyerowitz EM. The ABCs of floral homeotic genes. Cell. 1994; 78(2):203-9. https://doi.org/10.1016/0092-8674(94)90291-7.

56. Coen ES, Meyerowitz EM. The war of the whorls: genetic interactions controlling flower development. Nature. 1991;353(6339):31-7. https://doi. org/10.1038/353031a0.

57. Bowman JL, Smyth DR, Meyerowitz EM. The ABC model of flower development: then and now. Development. 2012;139(22):4095-8. https:// doi.org/10.1242/dev.083972.

58. Mandel MA, Yanofsky MF. The Arabidopsis AGL9 MADS box gene is expressed in young flower primordia. Sex Plant Reprod. 1998;11(1):22-8. https://doi.org/10.1007/s004970050116.

59. Poupin MJ, Federici F, Medina C, Medina C, Matus JT, Timmermann T, ArceJohnson P. Isolation of the three grape sub-lineages of B-class MADS-box TM6, PISTILLATA and APETALA3 genes which are differentially expressed during flower and fruit development. Gene. 2007;404(1-2):10-24. https://doi. org/10.1016/j.gene.2007.08.005.

60. Coll NS, Smidler A, Puigvert M, Popa C, Valls M, Dangl JL. The plant metacaspase AtMC1 in pathogen-triggered programmed cell death and aging: functional linkage with autophagy. Cell Death Differ. 2014;21(9):1399408. https://doi.org/10.1038/cdd.2014.50.

61. Bartel DP. MicroRNAs: genomics, biogenesis, mechanism, and function. Cell. 2004;116(2):281-97. https://doi.org/10.1016/S0092-8674(04)00045-5.

62. Mu JY, Tan HL, Hong SL, Liang Y, Zuo JR. Arabidopsis transcription factor genes NF-YA1, 5, 6, and 9 play redundant roles in male gametogenesis, embryogenesis, and seed development. Mol Plant. 2013;6(1):188-201. https://doi.org/10.1093/mp/sss061.

63. Yu DS, Li X, Zhao XS, Zhao XY, Du CQ, Chen J, Li CY, Sun MS, Wang L, Lin JZ, Tang DY, Yu F, Liu XM. RPN1 a negatively regulates ABA signaling in Arabidopsis. Plant Physiol Biochem. 2016;108:279-85. https://doi.org/10.101 6/j.plaphy.2016.06.012.

64. Martín-Trillo M, Cubas P. TCP genes: a family snapshot ten years later. Trends in Plant Sci. 2010;15(1):31-9. https://doi.org/10.1016/j.tplants.2009.11.003.

65. Pan XQ, Welti R, Wang XM. Quantitative analysis of major plant hormones in crude plant extracts by high-performance liquid chromatography-mass spectrometry. Nat Protoc. 2010;5(6):986-92. https://doi.org/10.1038/nprot.2 010.37.

66. Grabherr MG, Haas BJ, Yassour M, Levin JZ, Thompson DA, Amit I, Xian A, Fan L, Raychowdhury R, Zeng QD, Chen ZH, Mauceli E, Hacohen N, Lindblad K, Friedman N, Regev A. Trinity: reconstructing a full-length transcriptome without a genome from RNA-Seq data. Nat Biotechnol. 2011; 29(7):644-52. https://doi.org/10.1038/nbt.1883.

67. Pertea $G$, Huang $X Q$, Liang F, Antonescu V, Sultana R, Karamycheva S, Lee $Y$, White J, Cheung F, Parvizi B, Tsai J. Quackenbush. TIGR gene indices clustering tools (TGICL): a software system for fast clustering of large EST datasets. Bioinformatics. 2003;19(5):651-2. https://doi.org/10.1093/bioinforma tics/btg034.

68. Love Ml, Huber W, Anders S. Moderated estimation of fold change and dispersion for RNA-seq data with DESeq2. Genome Biol. 2014;15(12):550. https://doi.org/10.1186/s13059-014-0550-8

69. Langmead B, Trapnell C, Pop M, Salzberg SL. Ultrafast and memory-efficient alignment of short DNA sequences to the human genome. Genome Biol. 2009;10(3):R25. https://doi.org/10.1186/gb-2009-10-3-r25.

70. Evers $M$, Huttner $M$, Dueck A, Meister G, Engelmann JC. miRA: adaptable novel miRNA identification in plants using small RNA sequencing data. BMC Bioinformatics. 2015;16(1):1-10.

71. Wu HJ, Ma YK, Chen T, Wang M, Wang XJ. PsRobot: a web-based plant small RNA meta-analysis toolbox. Nucleic Acids Res. 2012;40(W1):W22-8. https://doi.org/10.1093/nar/gks554.

72. Bonnet $\mathrm{E}, \mathrm{He} \mathrm{Y}$, Billiau $\mathrm{K}$, Van de Peer $\mathrm{Y}$. TAPIR, a web server for the prediction of plant microRNA targets, including target mimics. Bioinformatics. 2010;26(12):1566-8. https://doi.org/10.1093/bioinformatics/ btq233.

73. Fahlgren N, Carrington JC. miRNA target prediction in plants. Methods Mol Biol. 2010:592:51-7.

74. Wang LK, Feng ZX, Wang XW, Zhang XG. DEGseq: an R package for identifying differentially expressed genes from RNA-seq data. Bioinformatics. 2010;26(1):136-8. https://doi.org/10.1093/bioinformatics/btp612.

75. Akagi T, Shirasawa K, Nagasaki H, Hirakawa H, Tao R, Comai L, Henry IM. The persimmon genome reveals clues to the evolution of a lineage-specific sex determination system in plants. PLoS Genet. 2020;16(2):e1008566. https:// doi.org/10.1371/journal.pgen.1008566.

76. Suo YJ, Sun P, Cheng HH, Han WJ, Diao SF, Li HW, Mai YN, Zhao X, Li FD, Fu $J M$. A high-quality chromosomal genome assembly of Diospyros oleifera Cheng. GigaScience. 2020;9(1):giz164.

77. Du GG, Wang LY, Li HW, Sun P, Fu JM, Suo YJ, Han WJ, Diao SF, Mai YN, Li FD. Selection and validation of reference genes for quantitative gene expression analyses in persimmon (Diospyros kaki Thunb.) using real-time quantitative PCR. Biol Futura. 2019;70(4):261-7. https://doi.org/10.1556/019. 70.2019 .24 .

\section{Publisher's Note}

Springer Nature remains neutral with regard to jurisdictional claims in published maps and institutional affiliations.
Ready to submit your research? Choose BMC and benefit from:

- fast, convenient online submission

- thorough peer review by experienced researchers in your field

- rapid publication on acceptance

- support for research data, including large and complex data types

- gold Open Access which fosters wider collaboration and increased citations

- maximum visibility for your research: over $100 \mathrm{M}$ website views per year

At $\mathrm{BMC}$, research is always in progress.

Learn more biomedcentral.com/submissions 